\title{
Determination of field scale ammonia emissions for common slurry spreading practice with two independent methods
}

\author{
J. Sintermann ${ }^{1}$, C. Ammann ${ }^{1}$, U. Kuhnn ${ }^{1, *}$, C. Spirig ${ }^{1,{ }^{* *}}$, R. Hirschberger ${ }^{2}$, A. Gärtner ${ }^{3}$, and A. Neftel ${ }^{1}$ \\ ${ }^{1}$ Swiss Federal Research Station Agroscope Reckenholz-Tänikon ART - Air Pollution and Climate, Zürich, Switzerland \\ ${ }^{2}$ Engineering consultants Niemann and Partner, University of Bochum, Bochum, Germany \\ ${ }^{3}$ Northrhine-Westphalian Agency for Nature, Environment and Consumer Protection, Recklinghausen, Germany \\ * now at: Institut für Energie- und Klimaforschung Troposphäre (IEK-8) Forschungszentrum Jülich, Jülich, Germany \\ *** now at: Swiss Federal Office of Meteorology and Climatology MeteoSwiss, Zürich, Switzerland
}

Received: 6 April 2011 - Published in Atmos. Meas. Tech. Discuss.: 6 May 2011

Revised: 8 August 2011 - Accepted: 31 August 2011 - Published: 9 September 2011

\begin{abstract}
At a cropland and a grassland site field scale ammonia $\left(\mathrm{NH}_{3}\right)$ emissions from slurry application were determined simultaneously by two approaches based on (i) eddy covariance (EC) flux measurements using high temperature Chemical Ionisation Mass Spectrometry (HT-CIMS) and on (ii) backward Lagrangian Stochastic (bLS) dispersion modelling using concentration measurements by three optical open path Fourier Transform Infrared (FTIR) systems. Slurry was spread on the fields in sequential tracks over a period of one to two hours. In order to calculate field emissions, measured EC/HT-CIMS fluxes were combined with flux footprint analysis of individual slurry spreading tracks to parameterise the $\mathrm{NH}_{3}$ volatilisation with a bi-exponential time dependence. Accordingly, track-resolved concentration footprints for the FTIR measurements were calculated using bLS. A consistency test with concentrations measured by impingers showed very low systematic deviations for the EC/HT-CIMS results $(<8 \%)$ but larger deviations for the bLS/FTIR results. For both slurry application events, the period during fertilisation and the subsequent two hours contributed by more than $80 \%$ to the total field emissions. Averaged over the two measurement methods, the cumulated emissions of the first day amounted to $17 \pm 3 \%$ loss of applied total ammoniacal nitrogen over the cropland and $16 \pm 3 \%$ over the grassland field.
\end{abstract}

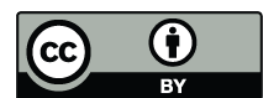

Correspondence to: J. Sintermann (joerg.sintermann@art.admin.ch)

\section{Introduction}

The growing demand for food and energy products has lead to highly intensified agriculture with increasing emissions of nitrogen-containing compounds that pose environmental risks. One of the particularly important trace gas species in emissions associated with agriculture is ammonia $\left(\mathrm{NH}_{3}\right)$ (Aneja et al., 2008). This anthropogenic $\mathrm{NH}_{3}$ release contributes to a large extent to the harmful effects of high reactive nitrogen loads (Galloway et al., 2003; Erisman et al., 2007). In central Europe, agricultural $\mathrm{NH}_{3}$ volatilisation accounts for more than $90 \%$ of the release (Erisman et al., 2008; Reis et al., 2009) and $\mathrm{NH}_{3}$ emissions following organic livestock waste application on fields have been identified to amount for roughly a third to half of the agricultural $\mathrm{NH}_{3}$ losses (Reidy et al., 2008a,b; EEA, 2009). A detailed quantification of $\mathrm{NH}_{3}$ emissions with high accuracy is essential for a better knowledge about the factors controlling $\mathrm{NH}_{3}$ volatilisation after application of organic fertiliser (Erisman et al., 2008; Zhang et al., 2008). Such measurements are vital for the characterisation of the agricultural nitrogen budget (Ammann et al., 2009) as well as to link emissions and monitoring, and hence to assess abatement strategies (Bleeker et al., 2009; Erisman et al., 2009).

In the literature, a very large range of $\mathrm{NH}_{3}$ loss factors related to the application of slurry to agricultural surfaces (as percentage of the applied total ammoniacal nitrogen: TAN) is found. It comprises values between $4 \%$ to almost $100 \%$ (e.g. Pain et al., 1989; Braschkat et al., 1997; Vandre et al., 1997; Génermont et al., 1998; Menzi et al., 1998; Huijsmans et al., 2001; Søgaard et al., 2002; Huijsmans et al., 2003; Misselbrook et al., 2002, 2005a; Sanz et al., 2010; Spirig et al., 2010; Uusi-Kämppä and Mattila, 2010). The strong

Published by Copernicus Publications on behalf of the European Geosciences Union. 
stickiness of the polar $\mathrm{NH}_{3}$ molecule complicates measurements of ambient $\mathrm{NH}_{3}$ concentrations (Parrish and Fehsenfeld, 2000; von Bobrutzki et al., 2010) and consequently fluxes. Varying instrumental performance (Milford et al., 2009; Sutton et al., 2009) and limited signal range of sensors (Spirig et al., 2010) introduce large uncertainties into $\mathrm{NH}_{3}$ emission quantifications. The possibility for accurate field scale assessments under common agricultural practice is important for the validation of emission levels (Sommer et al., 2003; Spirig et al., 2010). Agricultural practice means that the slurry spreading is not performed instantaneously, but as a sequence of dispersals over a period of typically one to several hours. Thus, the fertilised field does not represent a homogeneous area source for $\mathrm{NH}_{3}$. In addition, the emission rate of freshly applied slurry can show a fast decrease (Sintermann et al., 2011). These spatial and temporal inhomogeneity effects have to be considered when evaluating emission losses on the field scale.

In the present paper, we report on two experiments in $\mathrm{Au}-$ gust 2009, devoted to quantify the field scale $\mathrm{NH}_{3}$ emissions associated with spreading of slurry in high temporal resolution. We present two methods to determine these emissions. The first is based on direct flux measurements by the eddy covariance (EC) method using fast high temperature Chemical Ionisation Mass Spectrometry (HT-CIMS) with a high temperature inlet line (Sintermann et al., 2011) in combination with a detailed flux footprint attribution. The HTCIMS instrument derives from the common Proton Transfer Reaction-Mass Spectrometer (PTR-MS) and uses electron transfer reactions for $\mathrm{NH}_{3}$ ionisation. The second approach uses open path line concentration measurements by optical Fourier Transform Infrared (FTIR) systems in combination with a backward Lagrangian Stochastic (bLS) dispersion model (Flesch et al., 2004) for concentration footprint attribution. For $\mathrm{NH}_{3}$ flux measurements, the EC/HTCIMS approach has the advantage that wall interaction are minimised by strong heating of all surfaces and their impact on the EC flux can be quantified. The bLS/FTIR method is based on inlet-free measurements and links the downwind $\mathrm{NH}_{3}$ concentration to its source. The two methods have been applied simultaneously on two slurry spreading events, one on a cropland and the other on a grassland field in Oensingen, Switzerland. The results of both approaches are intercompared and discussed in view of previous micrometeorological measurements at the site with a wet chemical gradient system (Spirig et al., 2010).

\section{Methods}

\subsection{Analytical techniques for $\mathrm{NH}_{3}$ detection}

\subsubsection{HT-CIMS}

The HT-CIMS, based on PTR-MS (Hansel et al., 1995; Lindinger et al., 1998), is a chemical ionisation technique making use of electron transfer reactions to on-line ionise continuously sampled gas with subsequent detection of selected ion products (Norman et al., 2007, 2009). It operates with positively charged oxygen instead of protonated water as a source for charge transfer. A detailed description of the instrumental principles is given by Norman et al. (2007). In order to obtain a fast time response $(\sim 1 \mathrm{~s})$ for $\mathrm{NH}_{3}$ we employed the instrument in a modified way including an adopted inlet scheme and a prototype drift tube of reduced volume and altered materials, heated to $180^{\circ} \mathrm{C}$. Measuring ambient $\mathrm{NH}_{3}$ concentrations and EC fluxes, the HT-CIMS sub-sampled gas at the downstream end of a $23 \mathrm{~m}$ $1 / 2^{\prime \prime}$ PFA (OD) tube, heated to $150^{\circ} \mathrm{C}$ and flushed with 100 STP $1 \mathrm{~min}^{-1}$. The air intake was located $1 \mathrm{~m}$ above ground level (ma.g.l.) adjacent to an ultrasonic anemometer (HS Research Anemometer, Gill Instruments Ltd, Lymington, UK) mounted at a height of $1.25 \mathrm{~m}$ a.g.l. The operation of the instrument and the entire flux setup, along with analyses confirming a sufficiently fast time response of the system for EC flux measurements are described by Sintermann et al. (2011). The HT-CIMS was calibrated before every fertilisation against an $\mathrm{NH}_{3}$ permeation device (LN Industries, Geneva, Switzerland) equipped with a permeation tube (VICI, Metronics Inc., Poulsbo, WA, USA). The permeation rate was determined with impingers.

\subsubsection{FTIR}

With the purpose to monitor the $\mathrm{NH}_{3}$ concentration profile downwind of the slurry emissions, three open path FTIR systems (K300, Kayser-Threde GmbH, München, Germany) in bi-static configuration were installed at three heights: $0.8,1.8$ and $3.0 \mathrm{~m}$ a.g.l. on 4 August 2009 and 0.8, 1.9 and $3.0 \mathrm{~m}$ a.g.l. on 6 August 2009, respectively. Path integrated $\mathrm{NH}_{3}$ concentrations with a time resolution of about 2 min over lengths of $109 \mathrm{~m}$ on 4 August and $58 \mathrm{~m}$ on 6 August were obtained. The FTIR measurements (e.g. Gärtner et al., 2008) are based on interferometric analysis of infrared $\mathrm{NH}_{3}$ absorption spectra using Fourier transformation (Hirschberger, 2000). The specific configuration of the applied systems is described in detail by Heise et al. (2001). The detecting units were of MCT (Mercury Cadmium Telluride) and light source was a GLOBAR (glowing bar, silicium carbide) operated at $1500^{\circ} \mathrm{C}$, resulting in broad band infrared irradiation. The systems were calibrated 2 weeks prior to the experiment. This was done with a multi-reflection cell (white cell, Bastian Feinmechanik, Wuppertal, Germany) using calibration 
Table 1. Impinger measurements; positions as displayed in Fig. 1.

\begin{tabular}{lcrrrr}
\hline & position & $\begin{array}{r}\text { sample height } \\
{[\mathrm{m} \text { a.g.1.] }}\end{array}$ & $\begin{array}{r}\text { sample time } \\
{[\mathrm{CET}]}\end{array}$ & $\begin{array}{r}\text { amount of sampled air } \\
{[\mathrm{moles}]}\end{array}$ & $\begin{array}{r}\mathrm{NH}_{3} \\
{\left[\mu \mathrm{g} \mathrm{m}^{-3}\right]}\end{array}$ \\
\hline 4 August 2009 & (a) & $0.45 / 1.45$ & $12: 47-14: 50$ & $5.41 / 5.73$ & $688 / 365$ \\
& (a) & $0.45 / 1.45$ & $14: 58-18: 55$ & $10.42 / 10.34$ & $153 / 79$ \\
& (b) & $0.45 / 1.45$ & $12: 55-15: 05$ & $5.61 / 5.35$ & $649 / 303$ \\
& (b) & $0.45 / 1.45$ & $15: 06-19: 12$ & $10.61 / 10.13$ & $131 / 68$ \\
\hline \multirow{2}{*}{ A August 2009 } & (a) & $0.45 / 1.45$ & $10: 15-12: 30$ & $6.02 / 5.72$ & $660 / 320$ \\
& (a) & $0.45 / 1.45$ & $12: 35-16: 15$ & $9.82 / 9.23$ & $141 / 52$ \\
& (b) & $0.45 / 1.45$ & $10: 17-12: 37$ & $6.18 / 6.00$ & $728 / 261$ \\
& (b) & 0.45 & $14: 23-16: 35$ & 5.83 & 82 \\
& (b) & 1.45 & $12: 38-16: 35$ & 10.15 & 29 \\
\hline
\end{tabular}

gas (Messer, Griessheim, Germany). Concentration calculations were performed by the software CLSEVAL (Müller, 2000). The detection limit for $\mathrm{NH}_{3}$ was about $15 \mu \mathrm{g} \mathrm{m}{ }^{-3}$ and the relative accuracy was estimated to better than $10 \%$.

\subsubsection{Cavity ring-down spectroscopy}

As with FTIR spectroscopy, cavity ring-down spectroscopy utilises the light absorption of $\mathrm{NH}_{3}$ in the infrared, measuring the ring-down time of a multiple reflected laser pulse (Berden et al., 2000). The instrument (G1103; Picarro Inc., California, USA) was housed in an air-conditioned container sampling ambient air at $5 \mathrm{~m}$ a.g.l. A $9.5 \mathrm{~m}$ long 1/4" OD PFA inlet tube was provided with a PTFE membrane filter $(5 \mu \mathrm{m}$ pore size; Whatman Ltd, Maidstone, UK) and the instrument sampled at a flow rate of $0.5 \mathrm{STP} 1 \mathrm{~min}^{-1}$. The analyser was run continuously during the experimental period to monitor $\mathrm{NH}_{3}$ background levels recording data in $3 \mathrm{~s}$ intervals. In field measurements, a setup including a comparable instrument had an effective time resolution of roughly 5 to 10 min (von Bobrutzki et al., 2010). In the present study, the recorded $\mathrm{NH}_{3}$ concentration were averaged over $10 \mathrm{~min}$. The instrument was calibrated before each fertilisation against the same permeation source as used for the HT-CIMS gas-phase calibrations (Sintermann et al., 2011). The relative accuracy was $10 \%$. In a side-by-side field intercomparison with the HT-CIMS under background conditions, absolute deviations were generally below $2 \mu \mathrm{g} \mathrm{m}^{-3}$.

\subsubsection{Sampling by impingers and laboratory analysis}

For comparison, $\mathrm{NH}_{3}$ concentrations over the fields were recorded with wet chemical impingers and subsequent laboratory analysis. Ambient air was directed at a controlled flow rate of $1 \mathrm{STP} 1 \mathrm{~min}^{-1}$ through acidic solution $\left(0.01 \mathrm{M} \mathrm{H}_{2} \mathrm{SO}_{4}\right)$ that ideally strips all gaseous $\mathrm{NH}_{3}$ and particulate $\mathrm{NH}_{4}^{+}$into dissolved $\mathrm{NH}_{4}^{+}$. The solution was spiked with $\mathrm{CH}_{2} \mathrm{O}$ to suppress microbial activity during sampling and storage. The air was aspirated by flow-controlled pumps
(Gilair-5, Sensidyne, Florida, USA). In addition, sample air flow was calibrated prior to and after each experiment. The impingers collected over periods of one to several hours. They had been tested for breakthrough of $\mathrm{NH}_{3}$ in the laboratory and during the field campaign by applying two impingers in series. The efficiency was $>99 \%$. A short $(15 \mathrm{~cm})$ $1 / 4^{\prime \prime}$ PFA inlet tube was added in front. Collected samples were immediately cooled to $4{ }^{\circ} \mathrm{C}$ and analysed off-line within 3 days by means of ion-chromatography. The device was calibrated using liquid $\mathrm{NH}_{4}^{+}$standards. Sampling periods, heights and sampled air volumes are shown in Table 1. Based on in-field side-by-side measurements and the precision of the laboratory calibration of the ion-chromatograph, the uncertainty of the impinger derived $\mathrm{NH}_{3}$ concentrations was estimated to be $3 \%$.

\subsection{Field experiment}

The experiments were conducted at an agricultural site (longitude $7^{\circ} 44^{\prime} \mathrm{E}$, latitude $47^{\circ} 17^{\prime} \mathrm{N}$, elevation $450 \mathrm{~m}$ a.s.l.) close to the town of Oensingen, located in the central lowland of Switzerland. Two adjacent fields cultivated as cropland (wheat) and intensively managed grassland (grass-clover mixture) were fertilised with liquid cattle slurry. The grassland is one of the level 3 sites of the NitroEurope project (www.nitroeurope.eu) and $\mathrm{NH}_{3}$ concentrations as well as exchange patterns had been investigated here previously (Norman et al., 2009; Spirig et al., 2010; Wolff et al., 2010; Flechard et al., 2010, 2011). The climate is temperate continental with mean annual temperature and rainfall of $9.5^{\circ} \mathrm{C}$ and $1200 \mathrm{~mm}$, respectively. The soil is classified as EutriStagnic Cambisol (FAO et al., 1998) developed on clayey alluvial deposits. Slurry was spread on the arable field (4 August) and on the grassland (6 August) using a tank trailer with splash plate. This is currently the most common slurry spreading technique in Swiss agriculture. Table 2 lists key parameters of the applied slurry. It consisted of a mixture of cattle (80\%) and aged pig (20\%) slurry on 4 August and 
Table 2. Characteristics of the applied slurry: $A_{\text {fert }}=$ fertilised area, $V_{\text {slurry }}=$ volume of applied slurry, $\mathrm{DM}=$ dry matter content, $\mathrm{N}_{\text {tot }}=$ total nitrogen content, TAN $=$ slurry total ammoniacal nitrogen $=\left[\mathrm{NH}_{4}^{+}\right]+\left[\mathrm{NH}_{3}\right] ; \pm$ standard deviation of the analytical sample replicates .

\begin{tabular}{lcccccc}
\hline & $\begin{array}{c}A_{\text {fert }} \\
{[\mathrm{ha}]}\end{array}$ & $\begin{array}{c}V_{\text {slurry }} \\
{\left[\mathrm{m}^{3}\right]}\end{array}$ & $\mathrm{pH}$ & $\begin{array}{c}\mathrm{DM} \\
{[\%]}\end{array}$ & $\begin{array}{c}\mathrm{N}_{\text {tot }} \\
{\left[\mathrm{g}{ }^{-1}\right]}\end{array}$ & $\begin{array}{c}\mathrm{TAN} \\
{\left[\mathrm{g}^{-1}\right]}\end{array}$ \\
\hline 4 August 2009 & 1.23 & 41.0 & $7.82 \pm 0.10$ & $0.99 \pm 0.09$ & $1.07 \pm 0.04$ & $0.87 \pm 0.01$ \\
6 August 2009 & 0.77 & 22.5 & $7.49 \pm 0.19$ & $2.03 \pm 0.35$ & $1.57 \pm 0.13$ & $1.18 \pm 0.05$ \\
\hline
\end{tabular}

of cattle slurry on 6 August. Corresponding to the typical practice on Swiss farms the slurry had been diluted with rain water during storage, resulting in a low dry matter (DM) content. The arable field had been harvested a few days earlier with stubbles of $\sim 20 \mathrm{~cm}$ height remaining in very low density, and the grassland field had been previously cut with a resulting average vegetation height of $5 \mathrm{~cm}$.

In order to distribute the slurry over the entire field, the farmer needed to spread several tank volumes and each refilling required 20 to $25 \mathrm{~min}$. Thereby, a sequence of fertilisation tracks composed of spatial and temporal displaced emission areas was produced (Fig. 1, chronologically numbered). The complete period of fertilisation took almost two hours on 4 August and about one hour on 6 August while individual slurry tracks were dispensed within $3 \mathrm{~min}$.

Figure 2 provides an overview over the predominant meteorological conditions for the days of fertilisation. Warmest air temperatures were $24^{\circ} \mathrm{C}$ and $27^{\circ} \mathrm{C}$, respectively, during daytime and no rainfall occurred. High solar radiation intensity was accompanied by relative humidity down to below $50 \%$ during the day with highest values in the early morning. Winds prevailed from north-easterly directions speeding up to $4 \mathrm{~m} \mathrm{~s}^{-1}$ and up to $2.5 \mathrm{~m} \mathrm{~s}^{-1}$, respectively.

The EC flux system (ultrasonic anemometer and sample gas intake connecting to the HT-CIMS) was placed on the field immediately after the distribution of the first slurry track had been completed. On 6 August it became necessary to subsequently move the system to the adjacent second track to provide a better fetch for the flux measurement. Hence, as soon as the second track was cast the EC system was positioned at its final location (Fig. 1). The FTIR systems measured $\mathrm{NH}_{3}$ concentrations spatially integrated over the length of the infrared paths. The data were averaged to obtain $10 \mathrm{~min}$ intervals. The optical paths were situated parallel to the south-western border of the respective field, stacked at the three heights. The paths were thus arranged orthogonal to the site's main wind axis, downwind of the expected wind direction. In addition, the cavity ring-down $\mathrm{NH}_{3}$ analyser was placed on the upwind edge of the fertilised field inside a temperature controlled container to monitor the $\mathrm{NH}_{3}$ background concentration, i.e. unaffected by local emissions. $\mathrm{NH}_{3}$ was sampled by the wet chemical impingers with subsequent laboratory analysis in order to provide a robust concentration measurement over the fertilised fields (Sect. 3.4). Immediately following both fertilisations - after the distribution of the slurry on the entire field - two towers equipped with impingers at two heights were positioned at each field. They captured $\mathrm{NH}_{3}$ concentrations integrated over one to several hours (Table 1).

\subsection{Determination of $\mathrm{NH}_{3}$ fluxes and quantification of field emissions}

\subsubsection{Eddy covariance method with fast HT-CIMS detection (EC/HT-CIMS)}

The procedure to calculate the EC fluxes (Dabberdt et al., 1993) of $\mathrm{NH}_{3}$ measured by HT-CIMS is described by Sintermann et al. (2011). The EC fluxes were corrected for the amount of high-frequency attenuation in the used closed path system by an empirical ogive approach (Ammann et al., 2006). Fluxes were calculated in $10 \mathrm{~min}$ intervals and were rejected if stationarity was violated according to Foken and Wichura (1996) (using 2.5 min sub-intervals). Data derived from all applied measurement systems are explicitly shown for the period when integral turbulence characteristics (Foken and Wichura, 1996) indicated conditions with turbulent exchange.

The application of slurry creates a non-stationary setting where areas of high slurry emissions are surrounded by plots with very small background $\mathrm{NH}_{3}$ fluxes close to zero. This evokes vertical flux divergence influencing the flux measured at a specific height (Fowler and Duyzer, 1989; Loubet et al., 2009). In order to deduce surface emissions from the EC measurements the flux divergence has to be considered. The flux footprint describes the upwind area determining an EC flux. It reflects the spatial density distribution of the flux at the measurement location (Schmid, 2002). In our experiment, several of the individually emitting slurry tracks intersected with the footprint area as well as fractions of unfertilised regions beyond the field boundaries, and footprint analysis (Neftel et al., 2008) was used to correct for the divergence. For the situation of high slurry $\mathrm{NH}_{3}$ emissions it was reasonable to assume negligible surface fluxes outside the fertilised field. The applied footprint model is based on the analytical algorithm by Kormann and Meixner (2001). It has been tested in a tracer experiment (Tuzson et al., 2010) 


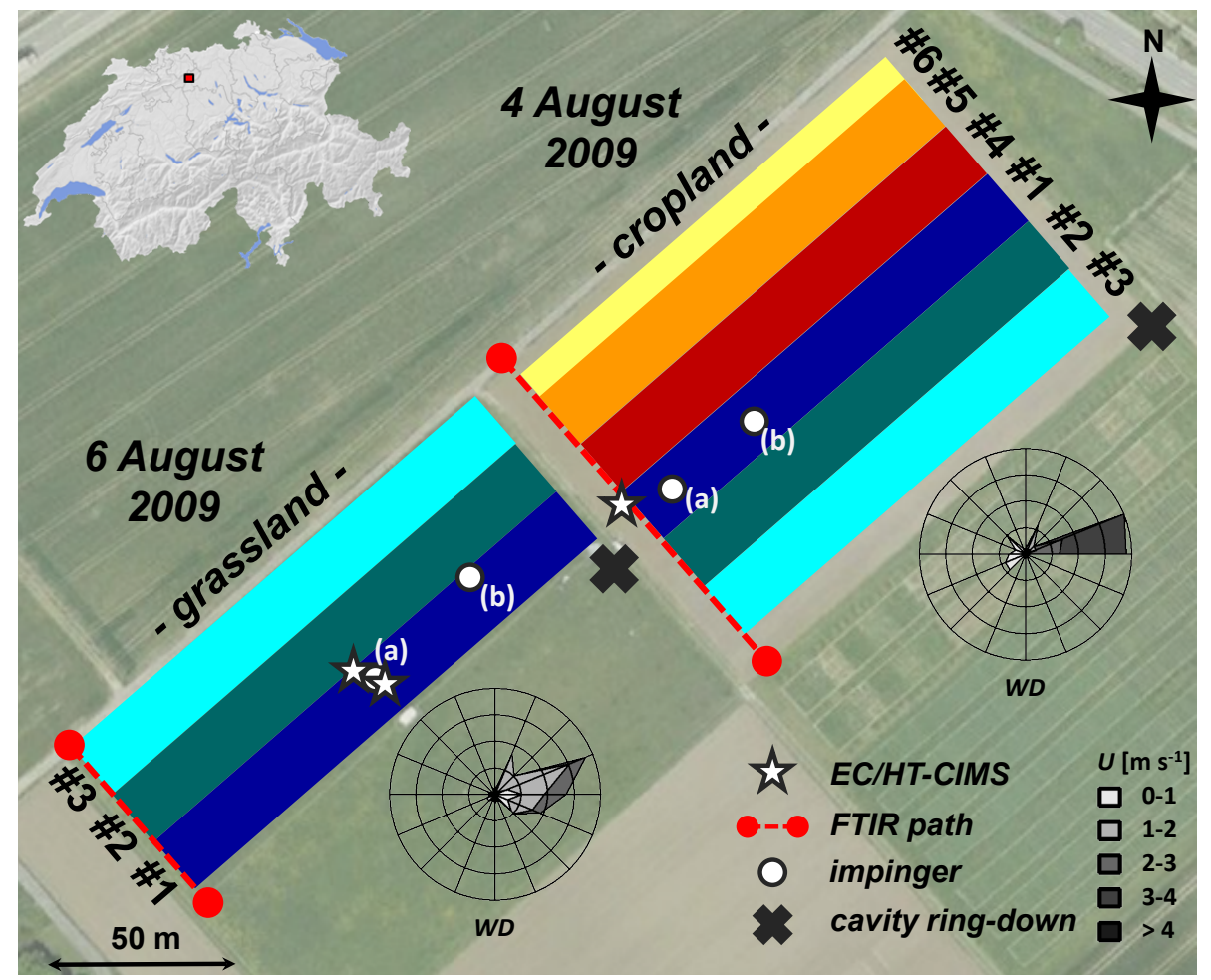

Fig. 1. Application of liquid cattle slurry by sequential spreading of six tanks (tracks \#1...\#6 on the cropland on 4 August 2009) and three tanks (tracks \#1...\#3 on the grassland on 6 August 2009), respectively, including wind direction (WD) and wind speed (U) from the start of slurry application until the end of the respective day; locations of measurement systems are displayed, (a) and (b) denote different impinger positions, EC/HT-CIMS position on 6 August on \#1 only temporary until \#2 was dispensed; satellite image: (CGoogle Inc., 2010.

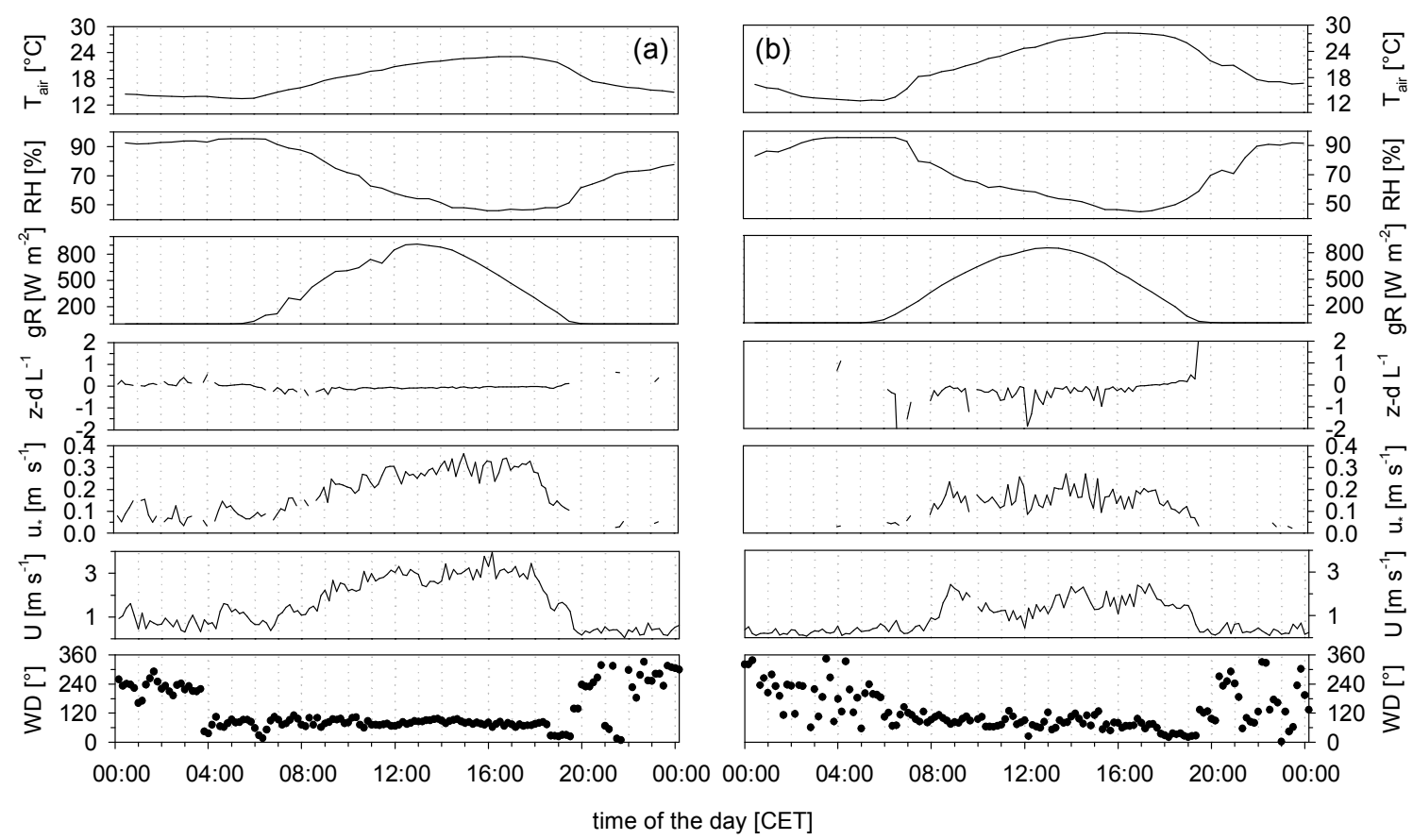

Fig. 2. Air temperature $\left(T_{\text {air }}\right)$, relative humidity $(\mathrm{RH})$, global radiation $(\mathrm{gR})$, stability $\left(z-d L^{-1}, z-d=1 \mathrm{~m}\right.$, where $z=$ measurement height, $d=$ displacement height, $L=$ Obukhov length), friction velocity $\left(u_{*}\right)$, wind speed $(U)$ and wind direction (WD) (Tair, RH, gR, WD and $U$ measured at 3 m a.g.l.; $L$ and $u_{*}$ measured at $\sim 1$ m a.g.l.) on (a) 4 August 2009 and (b) 6 August 2009. 
and has performed well in a state-of-the-art footprint intercomparison (Kljun et al., 2003). The footprint correction for flux divergence is valid, given (i) negligibly small flux interference of chemical conversion of $\mathrm{NH}_{3}$ to particulate $\mathrm{NH}_{4}^{+}$ between the surface and measurement level with the high emissions following fertilisation (Nemitz et al., 2009), and (ii) the small impact of storage of $\mathrm{NH}_{3}$ in the corresponding air column on the measured flux $(<1 \%$, determined following Spirig et al., 2010).

Specifically, with the footprint analysis the relative contributions of each slurry track and outer regions to the measured EC fluxes were quantified. By linear combination of the various track footprint fractions with a representative individual track emission over time we calculated the whole field's emissions. As proposed by Denmead et al. (1977) a characteristic time course of $\mathrm{NH}_{3}$ volatilisation, represented by a function $F_{\text {volat }}(t)$, was assumed to be equal for each track. The equality assumption was reasonable because the site conditions were about uniform for the field as a whole (regarding soil, vegetation cover, surface roughness and also meteorological properties) and the applied slurry was taken from the same source and was homogenised before bringing it to the field. The $\mathrm{NH}_{3}$ flux at the position of the EC system $\left(F_{\mathrm{EC}}\right)$ could then be written as the sum $(i=1$ to the number of tracks $n_{\mathrm{T}}$ ) of the emission from each track adjusted for the individual application time $\left(t_{0 i}\right)$ and weighted with the corresponding footprint fractions $\left(\Phi_{i}\right)$ :

$F_{\mathrm{EC}}(t)=\sum_{i=1}^{n_{\mathrm{T}}} \Phi_{i}(t) \cdot F_{\text {volat }}\left(t-t_{0 i}\right)$.

Denmead et al. (1977) chose an exponential decrease as shape for $F_{\text {volat }}(t)$ due to emissions from tracks fertilised with injected anhydrous $\mathrm{NH}_{3}$. At the Oensingen grassland site, Spirig et al. (2010) estimated the $\mathrm{NH}_{3}$ emissions associated with slurry application to decrease about exponentially to bi-exponentially in the period during and following the spreading, albeit with some uncertainty in the first up to three hours. In the present study, supported by visual inspection of the measured fluxes, we used a bi-exponential decay function (for a discussion of possible related processes see Sect. 4.3) with a total of four fittable parameters as course of $F_{\text {volat }}(t)$ :

$F_{\text {volat }}\left(t-t_{0}\right)=F_{1} \cdot \exp \left(-\frac{t-t_{0}}{\tau_{1}}\right)+F_{2} \cdot \exp \left(-\frac{t-t_{0}}{\tau_{2}}\right)$,

where the $\mathrm{NH}_{3}$ emission $F_{\text {volat }}$ at a time $t$ after the moment of slurry application $t_{0}$ is a combination of two exponential functions with coefficients $F_{1}$ and $F_{2}$, and decay times $\tau_{1}$ and $\tau_{2}$. $F_{1}+F_{2}$ yields the theoretical initial flux $F_{\text {ini }}$ directly at the very beginning of the emissions.

Equation (2) was best-fitted to the respective measured EC fluxes by adjusting the four constants $F_{1}, \tau_{1}, F_{2}, \tau_{2}$ in combination with the relative footprint fractions. The function's coefficients were determined by iterative minimisation (Newton type algorithm) of the sum of square deviations of the fit- ted to measured flux values. The choice of the specific function for the course of $F_{\text {volat }}$ will be justified by good correspondence of fit and measurements. For this procedure, values were taken into account over the period of the day when meteorological drivers for slurry $\mathrm{NH}_{3}$ volatilisation, like $U$ and $u_{*}$ remained about constant. In the following, we use the term $F_{\text {volat,EC }}$ to refer to the parameterised individual track emissions derived from the EC/HT-CIMS measurements and the fitting procedure. The fluxes calculated for the position of the EC system, derived by the combination of Eq. (1) and $F_{\text {volat,EC }}$ are denomiated $F_{\mathrm{EC} \text {,fit }}$. To estimate the field's average emission strength over time $F_{\text {field }}(t)$ the track emissions, weighted with the corresponding track areas (track area $A_{\mathrm{T}, i}$, hence field area $A_{\text {field }}=\sum_{i=1}^{n_{\mathrm{T}}} A_{\mathrm{T}, i}, A$ in $\mathrm{m}^{2}$ ), were combined considering the individual timing of slurry spreading:

$F_{\text {field }}(t)=\frac{1}{A_{\text {field }}} \sum_{i=1}^{n_{\mathrm{T}}} F_{\text {volat }}\left(t-t_{0 i}\right) \cdot A_{\mathrm{T}, i}$.

In the situation when only the first track had been applied and thus a single source area could be identified by the footprint evaluation, the measured EC flux combined with the respective footprint was used to compute the average field emissions at that time.

\subsubsection{Dispersion method using FTIR concentration measurements (bLS/FTIR)}

The FTIRs at the downwind field border measured mean path concentrations representing horizontally exported $\mathrm{NH}_{3}$ originating from the emissions. Since the infrared paths were on average not perpendicular to the prevailing wind direction, only a fraction of the field's $\mathrm{NH}_{3}$ export was comprised by the FTIR measurements. Correcting for the missing fraction has to account for the spatial inhomogeneity of the emissions due to the sequential slurry spreading. In order to relate the FTIR concentration measurements to surface emission fluxes a tool to determine the spatial dispersion of a tracer is necessary that can calculate concentration footprints (in analogy to the flux footprint). The bLS method (Flesch et al., 1995, 2004) is a powerful mean to determine emission rates employing a single (or multiple) downwind concentration measurement and vice versa. It is based on Lagrangian Stochastic and uses Monin-Obukhov similarity theory (MOST). The model calculates an ensemble of particle trajectories where the particles are being released at a given location and traced backward to determine the resulting particle-ground intersections at one or several areas. The applied bLS model is implemented in a freely available software called WindTrax (version 2.0.8.3, Thunder Beach Scientific, Halifax, Canada; www.thunderbeachscientific.com) that exhibits a graphical user interface (see review by Denmead, 2008). In the present study, a fixed number of 50000 particles was released to calculate particle-ground intersections. The software demands information about the atmospheric state and accepts input variables of gradual complexity levels, with 
preference to the most detailed inputs. The quantities are either specified directly using measured data and/or are estimated by WindTrax with the help of MOST. The software does not allow simultaneous input of $U$ and $u_{*}$, although it can be important to have $U$ and $u_{*}$ corresponding to the measured values in order to describe turbulence most accurately (Neftel et al., 2008). WindTrax rather computes $U$ from knowledge of $u_{*}, L$ and the roughness length of the underlying surface $\left(z_{0}\right.$ : height where the vertical profile of $U$ approaches zero) according to MOST. Therefore, we directly provided $\mathrm{WD}, u_{*}, L$, the standard deviations of the three wind vectors $u, v, w$, and $z_{0}$. Before, $z_{0}$ had been determined numerically with MOST using measured $u_{*}, L$ and $U(z-d)$ that define the vertical profile of $U$. Thus, it was assured that within WindTrax, $u_{*}$ and $U$ satisfied the actual measurements. The magnitude of $z_{0}$ could then be consulted to identify situations when atmosphere might not have sufficiently obeyed MOST (Laubach, 2010), which could lead to modelling errors (Flesch et al., 2004). All input variables were derived from the ultrasonic anemometer measurements of the EC system, and 10 min averaging intervals were used for the computations.

In WindTrax, the normalised concentration field $B(x, y, z)$ is determined (Laubach, 2010) from the downwind (c) and background $\left(c_{\mathrm{bgd}}\right)$ concentrations and the emission rate $\left(F_{\text {volat }}\right)$ :

$B(x, y, z, t)=\frac{c(x, y, z, t)-c_{\mathrm{bgd}}}{F_{\text {volat }}}$.

Calculating field emissions with bLS/FTIR consisted of two steps. First, WindTrax was applied to determine the relative contributions of individual slurry track emissions to the measured FTIR line concentrations. For this purpose, Eq. (4) was evaluated for the setup of the FTIR systems and the individual slurry track sources: the tracks were thus given unity emissions $\left(F_{\text {volat }}=1 \mu \mathrm{g} \mathrm{m}^{-2} \mathrm{~s}^{-1}\right)$ and in separate runs for each track the according $B_{\mathrm{FTIR}, i}(t)$ was computed. Next, the actual emissions were determined in a way similar to the procedure used above in case of the EC fluxes: the measured line concentrations $\left(c_{\mathrm{FTIR}}\right)$ were described as the sum of $c_{\mathrm{bgd}}$ and presumed individual track emissions $\left(F_{\text {volat }}(t)\right)$ adjusted by their footprint contributions $\left(B_{\mathrm{FTIR}, i}(t)\right)$,

$c_{\mathrm{FTIR}}(t)=c_{\mathrm{bgd}}(t)+\sum_{i=1}^{n_{\mathrm{T}}}\left(B_{\mathrm{FTIR}, i} \cdot F_{\text {volat }}\left(t-t_{0 i}\right)\right)$.

As with the EC fluxes, the time course of $F_{\text {volat }}$ (see Eq. 2) was assumed to be equal for each track, allowing the iterative determination of the parameters of $F_{\text {volat }}$ from the measured line concentrations and concentration footprints. In such, each fit for $F_{\text {volat }}$ obtained from a distinct height of FTIR measurement yielded one emission estimate, which should theoretically correspond to the emissions calculated from the other heights, provided equal performance of the single FTIR systems and realistic representation of dispersion in the bLS model. This parameterisation of individual track emissions derived from bLS/FTIR is henceforth termed $F_{\text {volat,FTIR, }}$ while $c_{\text {FTIR, fit }}$ is used to refer to the concentrations calculated for the FTIR paths based on the bLS concentration footprints (see Eq. 2) and $F_{\text {volat,FTIR. }}$

\subsection{Estimating initial volatilisation from liquid slurry characteristics}

By knowledge of the chemical slurry constituents and the physical parameters driving the $\mathrm{NH}_{3}$ volatilisation from solution one can calculate the theoretical flux arising from the initial $\mathrm{NH}_{3}$ volatilisation at the moment when the slurry is freshly exposed on the surface. Contrasting this slurry derived initial flux $\left(F_{\text {ini }}\right)$ to the corresponding initial flux determined from the respective $F_{\text {volat }}\left(t_{0}\right)$ (see Sect. 3.1) one may judge whether this initial flux was of a reasonable physicalchemical magnitude. Assuming immediate liquid-gas phase equilibrium and ideal solution, the initial $\mathrm{NH}_{3}$ concentration above the hypothetical slurry surface $c_{\text {ini }}\left(z_{0}^{\prime}\right)$ (for the concept of $z_{0}^{\prime}$ see e.g. Sutton et al., 1993) was inferred with the help of Henry's law (requiring slurry $\mathrm{pH},\left[\mathrm{NH}_{4}^{+}\right]$and surface temperature $T\left(z_{0}^{\prime}\right)$ ) (Spirig et al., 2010):

$c\left(z_{0}^{\prime}\right)=\frac{\left[\mathrm{NH}_{4}^{+}\right] \cdot 10^{4.1218-4507 / T\left(z_{0}^{\prime}\right)}}{\left[\mathrm{H}^{+}\right] \cdot 10^{-9}}$,

$c\left(z_{0}^{\prime}\right)$ in ppb and $T\left(z_{0}^{\prime}\right)$ in K. $c_{\text {ini }}\left(z_{0}^{\prime}\right)$ can be translated into the initial surface flux $F_{\text {ini }}$. A flux $F_{c}$ relates to $c\left(z_{0}^{\prime}\right)$ via the corresponding air concentration at a second height $c(z-d)$ and the aerodynamic and the viscous sublayer resistance $R_{\mathrm{a}}$ and $R_{\mathrm{b}}$ as defined in Flechard et al. (2010):

$F_{c}=\frac{c\left(z_{0}^{\prime}\right)-c(z-d)}{R_{\mathrm{a}}(z-d)+R_{\mathrm{b}}}$.

The $\mathrm{NH}_{3}$ concentration measured with the cavity ring-down system upwind of the fertilised fields was approximated as background concentration $c(z-d)$ at $20 \mathrm{~m}$ a.g.l. $F_{\text {ini }}$ was calculated from the initial slurry properties and atmospheric transport capacity using the gradient in $\mathrm{NH}_{3}$ concentrations. The surface temperature $T\left(z_{0}^{\prime}\right)$ was derived equivalent to Eq. (7), using the air temperature $T(z-d)$ and sensible heat flux, both measured by the ultrasonic anemometer at $1.25 \mathrm{~m}$ a.g.1.

\section{Results}

\subsection{Concentrations, fluxes, and emission rates by the EC/HT-CIMS method}

Over both fields, $\mathrm{NH}_{3}$ concentrations observed by the HTCIMS showed a typical pattern of a fast increase during the spreading of the slurry (Fig. 3). The highest recorded $10 \mathrm{~min}$ averaged concentrations were $817 \mu \mathrm{g} \mathrm{m}^{-3}$ on 4 August and $1543 \mathrm{\mu g} \mathrm{m}^{-3}$ on 6 August. Unfortunately, failures of the 


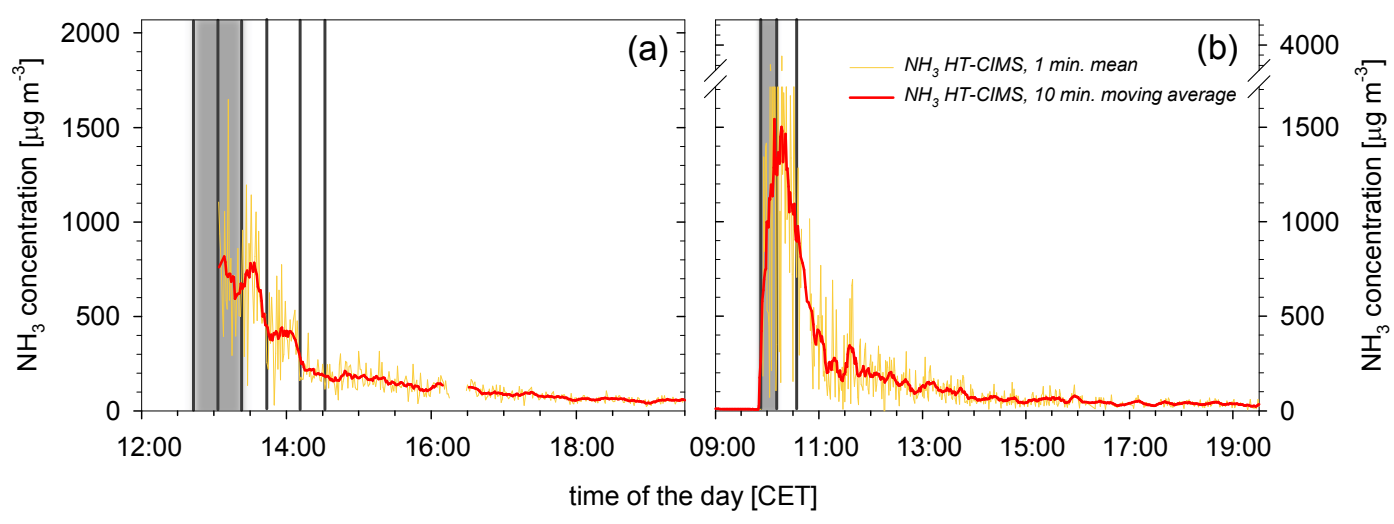

Fig. 3. $\mathrm{NH}_{3}$ concentrations measured by the HT-CIMS on (a) 4 August 2009 and (b) 6 August 2009; vertical bars represent the spreading of the individual slurry tracks (\#1... \#6 on 4 August 2009 and \#1...\#3 on 6 August 2009) while grey shaded areas indicate the period of slurry spreading that mainly affected the fetch of the measurement (Sintermann et al., 2011).

combined sonic and HT-CIMS data acquisition system resulted in short data gaps on 4 August, therefore during the very beginning of this fertilisation no measurement data were available. The concentration maximum was followed by a fast decrease down to about $60 \mu \mathrm{g} \mathrm{m}^{-3}$ and $30 \mu \mathrm{g} \mathrm{m}^{-3}$, respectively, in the evening.

On the days of both fertilisation events, the course of observed EC fluxes featured a similar pattern as the concentrations: an initial fast decrease followed by a slower decline dominating from roughly one hour after the slurry distribution for the rest of the day (Fig. 4). The measured $\mathrm{NH}_{3}$ fluxes were a composite of the emissions of the sequentially spread tracks. As shown in Fig. 4, the footprint analysis revealed that only tracks \#1 to \#3 on 4 August and tracks \#1 and \#2 on 6 August (as well as smaller fractions from outside the field) contributed with an approximately steady proportion to the EC flux. In the evenings, shifts in wind directions promoted increasing influence of the remaining tracks. It becomes evident that track \#1 contributed most to the respective measured EC flux on both days. The course of observed EC fluxes indicated an exponential to bi-exponential emission decrease as assumed for $F_{\text {volat }}$ (Eq. 2). Consequently, the fit function according to Eq. (1) could well reproduce the measured fluxes during almost the whole day (Fig. 5). The temporal fluctuations of the fitted fluxes represent changes in track footprint contributions influencing the flux at the EC location (see Fig. 4). Associated with a less constant WD, the fluctuations were stronger on 6 August. Median deviations between fitted and measured fluxes were about $11 \%$ on 4 August and $13 \%$ on 6 August considering values until 18:00 and 17:30, respectively. Afterwards, when the differences became larger, the field was assumed to emit homogeneously and average field emissions were calculated from the measured fluxes and a footprint analysis considering the field boundaries as a whole. Table 3 summarises the bi-exponential function parameters of $F_{\text {volat,EC }}$ as derived from the fitting procedure. The initial fast decays showed decay times $\tau_{1}$ of about 30 and 20 min while the slower decreases had time constants $\tau_{2}$ of roughly 2 and $3 \mathrm{~h}$. With $332 \mu \mathrm{g} \mathrm{m}^{-2} \mathrm{~s}^{-1}$ the fitted initial flux $F_{\text {ini }}$ immediately at the start of the volatilisation was almost twice as high on $6 \mathrm{Au}$ gust than with $170 \mu \mathrm{g} \mathrm{m}^{-2} \mathrm{~s}^{-1}$ on 4 August.

\subsection{Concentrations and emission rates by the bLS/FTIR method}

The vertical concentration profiles measured by the FTIR systems (Fig. 6) showed maximum $\mathrm{NH}_{3}$ concentrations (at $0.8 \mathrm{~m}$ a.g.1.) of $773 \mu \mathrm{g} \mathrm{m}^{-3}$ on 4 August and $1446 \mu \mathrm{g} \mathrm{m}^{-3}$ on 6 August, respectively. The course of concentrations approximately reflected the one observed with the HT-CIMS measurements. On 4 August, the values at the highest measurement level ( $3 \mathrm{~m}$ a.g.l.) mostly fell below the limit of detection at 18:00 in the evening. This happened to the $\mathrm{NH}_{3}$ measurements at all heights on the evening of 6 August.

The FTIR measurements were combined with respective bLS concentration footprints to parameterise $\mathrm{NH}_{3}$ volatilisa-

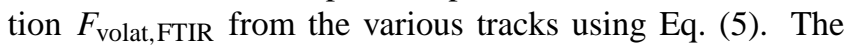
time course of measured $\mathrm{NH}_{3}$ concentrations was well reproduced by $c_{\mathrm{FTIR}, \text { fit }}$ before 18:00. $c_{\mathrm{FTIR}}$,fit began to deviate from measured values only in the evening, when the meteorological regime started to change. Then, the whole field was regarded to emit homogeneously and WindTrax was applied to calculate the respective field emissions. Apart from that evening period, median deviations between fitted and measured concentrations for the three heights (low to high) accounted for $6 \%, 6 \%$ and $22 \%$ on 4 August and for $19 \%$, $21 \%$ and $28 \%$ on 6 August.

Table 3 contains the characteristics of the derived biexponential functions describing the time course of a single track emission. The time constants $\tau_{1}$ of the first exponential function ranged from about 50 to $70 \mathrm{~min}$ on $4 \mathrm{Au}-$ gust and were around $30 \mathrm{~min}$ on 6 August for the results inferred from the three measurement heights. The second 


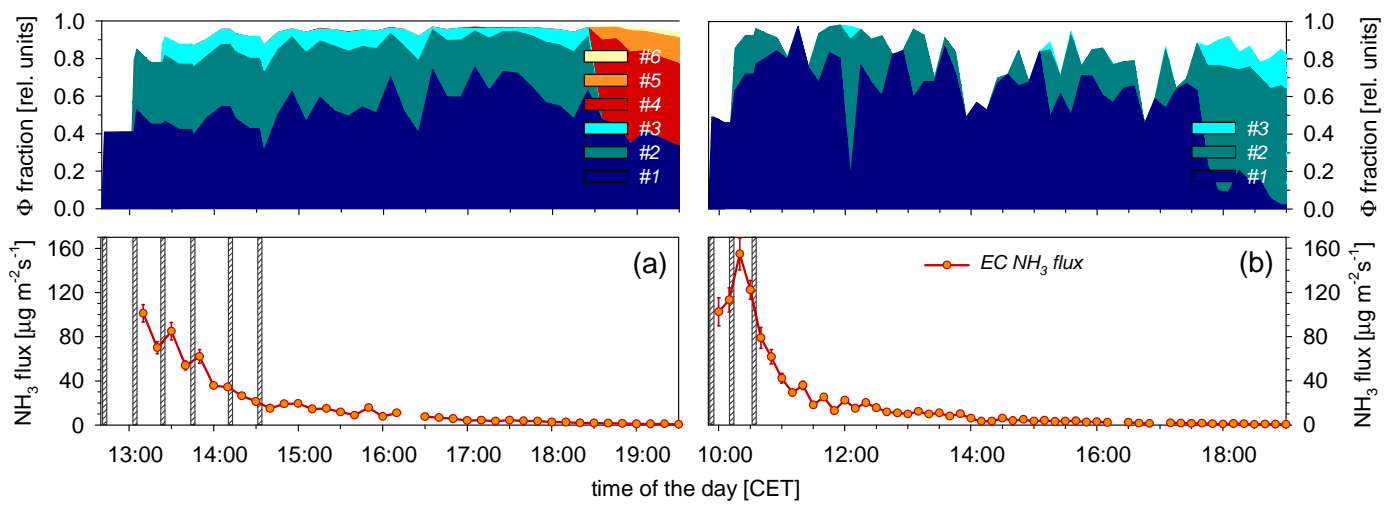

Fig. 4. Influence of the slurry tracks on the EC flux on (a) 4 August 2009 and (b) 6 August 2009 (6 and 3 tracks, respectively); upper panels: relative footprint $(\Phi)$ contributions of the individual slurry tracks to the EC flux measurement, white area displays the fraction of the flux footprint covering areas outside the fertilised tracks; lower panels: measured $\mathrm{EC} \mathrm{NH}_{3}$ flux, striped bars represent the actual time of the distribution of each track.
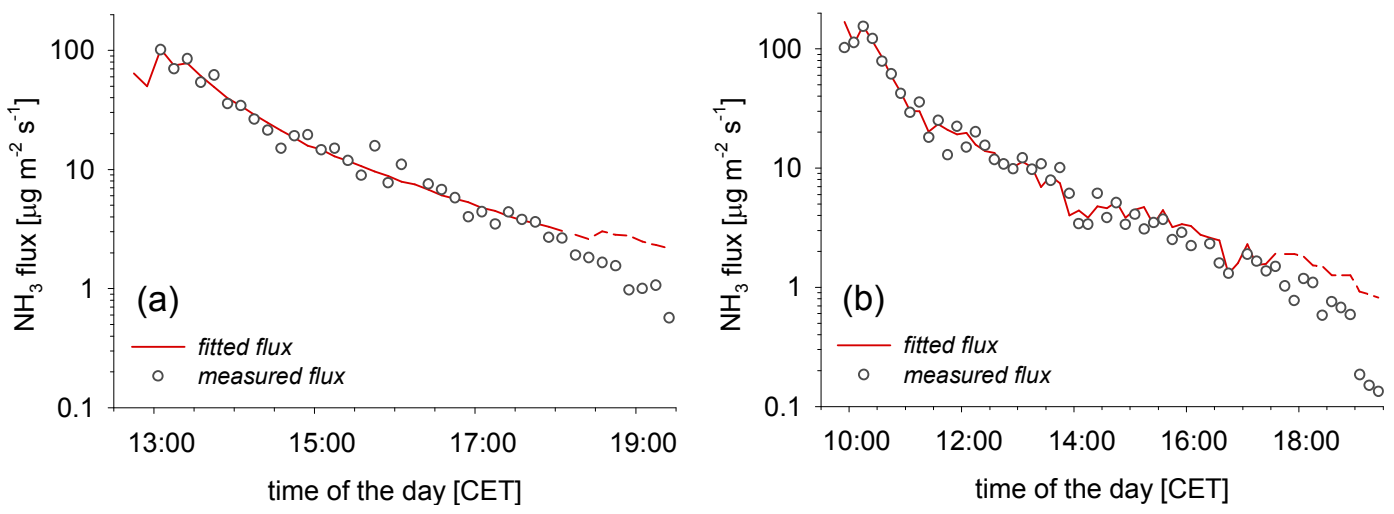

Fig. 5. EC NH 3 fluxes measured and corresponding $F_{\mathrm{EC} \text {,fit }}$ on (a) 4 August 2009 and (b) 6 August 2009; dashed lines indicate the periods when the parameterisation was regarded not to reflect representative surface emissions anymore, but the field was considered to emit homogeneously.

exponential function was of minor influence for the time course of the emissions on 4 August and had time constants $\tau_{2}$ larger than $4 \mathrm{~h}$ on 6 August. The initial flux $F_{\text {ini }}$ was between 144 and $202 \mu \mathrm{g} \mathrm{m}^{-2} \mathrm{~s}^{-1}$ on 4 August and between 206 to $252 \mu \mathrm{g} \mathrm{m}^{-2} \mathrm{~s}^{-1}$ on 6 August.

\subsection{Spatially averaged and cumulative field emissions}

The average field emissions (Eq. 3) increased step-wise during the actual period of fertilisation, which was of course associated with the distribution of the individual slurry tracks (Fig. 7). That was followed by an overall decline of emissions for the rest of the day. In the evening, when turbulence broke down, the $\mathrm{NH}_{3}$ field emissions became small (i.e. the concentration measurements by FTIR systems reached their detection limit and EC fluxes became very small and instationary). On both events, around 18:00 the field was considered to emit homogeneously over the whole field extent. In this transition regime the emissions decreased faster than would have been described by the bi-exponential time course. Looking at Figs. 2 and 7 it becomes clear that the change was caused by a shift in meteorological drivers. At around 18:00 essentially $U$ and $u_{*}$ sharply began to decrease, followed by a delayed increase in atmospheric stability. Almost at the same time, $T_{\text {air }}$ started to fall and RH began to rise.

At the cropland fertilisation (4 August), the track emis-

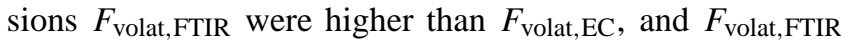
had a course closer to a single exponential function (Table 3). The resulting bLS/FTIR field emissions remained higher for the whole day. The parameters of the individually fitted functions $F_{\text {volat,EC }}$ and $F_{\text {volat,FTIR showed some }}$ considerable differences. The deviations were especially associated with the second exponential sub-function (Table 3), for which there is no reasonable explanation. However, these differences had only a smaller effect on the overall temporal course of emissions (see Fig. 7). Peak field emissions ranged from 88 to $72 \mu \mathrm{g} \mathrm{m}^{-2} \mathrm{~s}^{-1}$ for the bLS/FTIR fluxes and were 
Table 3. Parameters of the best-fitted bi-exponential functions, calculated surface temperature $\left(T\left(z_{0}^{\prime}\right)\right)$, and the according initial $\mathrm{NH}_{3}$ fluxes $\left(F_{\text {ini }}\right)$ as derived from Eq. $(2)$ and as expected from initial slurry equilibrium conditions.

\begin{tabular}{|c|c|c|c|c|c|c|c|}
\hline & & \multicolumn{4}{|c|}{ fitted function parameters } & \multirow[b]{2}{*}{$\begin{array}{c}T\left(z_{0}^{\prime}\right) \\
{[\mathrm{K}]}\end{array}$} & \multirow[b]{2}{*}{$\begin{array}{c}F_{\text {ini }} \\
{\left[\mu \mathrm{g} \mathrm{m}^{-2} \mathrm{~s}^{-1}\right]}\end{array}$} \\
\hline & & $\begin{array}{c}F_{1} \\
{\left[\mu \mathrm{g} \mathrm{m}^{-2} \mathrm{~s}^{-1}\right]}\end{array}$ & $\begin{array}{c}\tau_{1} \\
{[\mathrm{~min}]}\end{array}$ & $\begin{array}{c}F_{2} \\
{\left[\mu \mathrm{g} \mathrm{m}^{-2} \mathrm{~s}^{-1}\right]}\end{array}$ & $\begin{array}{c}\tau_{2} \\
{[\mathrm{~min}]}\end{array}$ & & \\
\hline \multirow[t]{5}{*}{4 August 2009} & EC/HT-CIMS & 134 & 32 & 36 & 129 & & 170 \\
\hline & $\mathrm{bLS} /$ FTIR $0.8 \mathrm{~m}$ & 192 & 49 & 10 & 2724674 & & 202 \\
\hline & $\mathrm{bLS} /$ FTIR $1.8 \mathrm{~m}$ & 150 & 60 & 6 & 74951 & & 156 \\
\hline & bLS/FTIR $3.0 \mathrm{~m}$ & 142 & 73 & 2 & 74951 & & 145 \\
\hline & slurry equil. & & & & & 302.9 & $564-894$ \\
\hline \multirow[t]{5}{*}{6 August 2009} & EC/HT-CIMS & 295 & 23 & 37 & 161 & & 332 \\
\hline & bLS/FTIR $0.8 \mathrm{~m}$ & 207 & 29 & 23 & 258 & & 230 \\
\hline & bLS/FTIR $1.9 \mathrm{~m}$ & 237 & 28 & 15 & 367 & & 252 \\
\hline & bLS/FTIR $3.0 \mathrm{~m}$ & 201 & 30 & 5 & 788 & & 206 \\
\hline & slurry equil. & & & & & 299.6 & $186-446$ \\
\hline
\end{tabular}
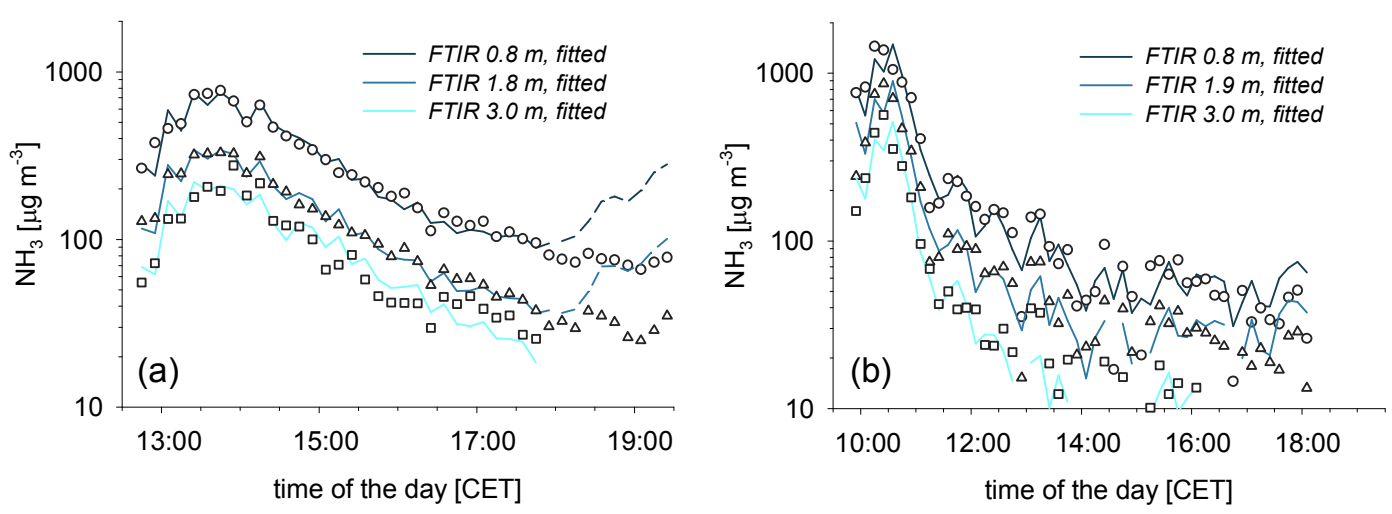

Fig. 6. $\mathrm{NH}_{3}$ concentrations measured by FTIR systems and corresponding $c_{\text {FTIR,fit }}$ on (a) 4 August 2009 and (b) 6 August 2009 ; open symbols show the measured values at the various measurement heights: circles $=0.8 \mathrm{~m}$, triangles $=1.8$ and $1.9 \mathrm{~m}, \mathrm{squares}=3.0 \mathrm{~m}$ a.g. $1 . ;$ dashed lines indicate periods when the parameterisation was regarded not to reflect representative surface emissions anymore, but the field was considered to emit homogeneously.

$66 \mu \mathrm{g} \mathrm{m}^{-2} \mathrm{~s}^{-1}$ for the EC/HT-CIMS emissions. Over grassland (6 August), the bLS/FTIR track emissions and hence the corresponding average field emissions were characterised by similar bi-exponential functions as those derived from the EC/HT-CIMS fluxes. The temporal behaviour of $F_{\text {volat,EC }}$ obeyed to the bi-exponentiality on both events in a similar way (except that $F_{\text {ini }}$ was much higher over the grassland). In contrast to 4 August, the EC/HT-CIMS field emissions were larger than the bLS/FTIR field emissions. Peak emissions occurred immediately after fertilisation. They were in maximum $174 \mu \mathrm{g} \mathrm{m}^{-2} \mathrm{~s}^{-1}$ and for the bLS/FTIR derived emissions, highest values amounted to 114 to $139 \mu \mathrm{g} \mathrm{m}^{-2} \mathrm{~s}^{-1}$. Although theoretically equivalent, the fluxes calculated from the FTIR concentrations at the three heights differed from each other. On 4 August, the emissions inferred from the concentrations of the lowest height exceeded those calculated from the measurements at both remaining heights, whereas on 6 August the fluxes derived from the uppermost height were smaller than those derived from the other two.

In terms of cumulated emissions (Fig. 8) the fertilised fields lost $5.35 \mathrm{~kg} \mathrm{~N}$ on 4 August and $4.88 \mathrm{~kg} \mathrm{~N}$ on $6 \mathrm{Au}-$ gust with regards to the EC/HT-CIMS derived results. On 4 August, the bLS/FTIR based losses were higher (6.69 to $7.90 \mathrm{~kg} \mathrm{~N}$ ) and lower ( 3.21 to $4.33 \mathrm{~kg} \mathrm{~N}$ ) on 6 August. Over the arable site, the bLS/FTIR cumulated emissions were about $20 \%$ (middle and highest measurement height) to $32 \%$ (lowest height) larger than the cumulated EC/HT-CIMS emissions. Over the grassland, they deviated from EC/HTCIMS by $-13 \%$ (middle and lowest height) and $-48 \%$ (highest height). According to both measurement systems over $80 \%$ of the total emissions occurred in the period during the slurry spreading and the two subsequent hours. 

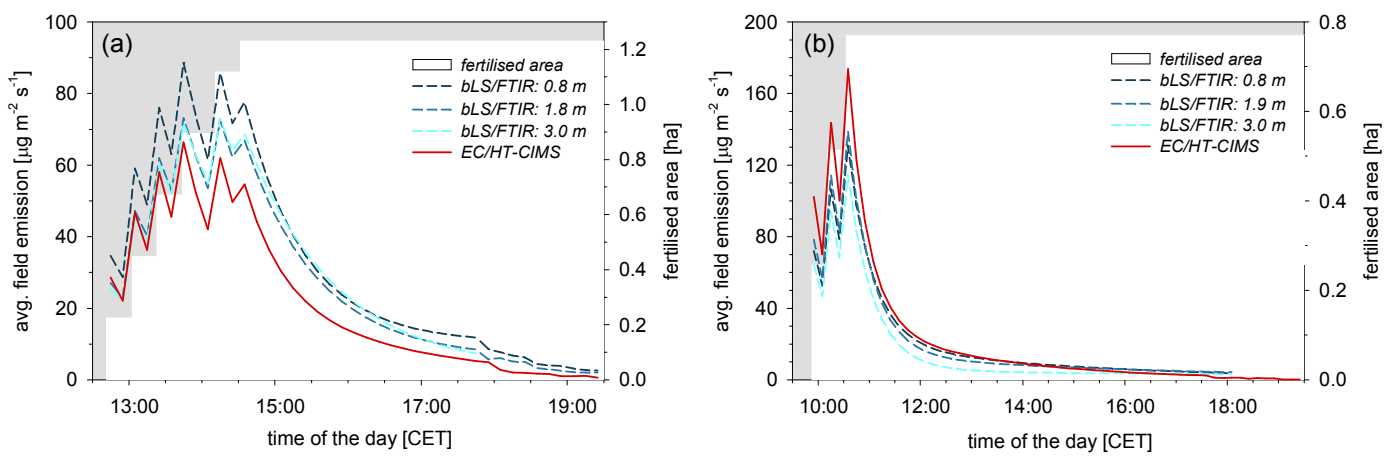

Fig. 7. Average field emissions on (a) 4 August 2009 and (b) 6 August 2009 derived from EC/HT-CIMS and bLS/FTIR.

Table 4 summarises the various estimates of overall $\mathrm{NH}_{3}$ field emission losses. Cumulated emissions over several days were calculated based on ongoing EC/HT-CIMS measurements over the second days after slurry spreading (whole field regarded to emit homogeneously). The field emissions were expected to decrease exponentially during 10 days at maximum (Flechard et al., 2010). The period subsequent to the days of fertilisation then contributed only to a very small degree to the overall $\mathrm{NH}_{3}$ losses, namely to about $7 \%$ and $4 \%$ of the first day's losses, respectively. Taking these fractions into account, the EC/HT-CIMS derived emissions represented $16 \%$ loss of the applied TAN for the cropland and $19 \%$ for the grassland site. The FTIR measurements were close to or below the detection limit on the days following the fertilisations and the systems' application period was restrained by their timely relocation between the measurement sites. The corresponding emission estimates therefore account exclusively for the first day of emissions. They comprise $18 \%$ to $22 \%$ loss of applied TAN on 4 August and $12 \%$ to $16 \%$ on 6 August, and when averaged over both measurement methods they amounted to $17 \pm 3 \%$ and $16 \pm 3 \%$, respectively.

\subsection{Verification of concentrations and derived emissions}

\subsubsection{Comparison with impinger concentration measurements}

The bLS model was used to calculate the expected $\mathrm{NH}_{3}$ concentration at the sampling locations of the impingers, using the fitted volatilisation functions $F_{\text {volat,EC }}$ and $F_{\text {volat,FTIR }}$ as source terms. Figure 9 illustrates the comparison of the observed impinger concentrations to the calculated concentrations, averaged over the different impinger sampling periods. Based on theoretical consideration and on visual inspection, we analysed the (dis-)agreement between the plotted concentrations by linear regression through zero (see slope and RMSE results in Table 5). With respect to the emissions based on EC/HT-CIMS, calculated and directly measured impinger concentrations showed a very good agree- ment without systematic deviations (Fig. 9, panel a). The regression slopes were close to 1 with an average uncertainty range of $\pm 8 \%$. The root mean squared error (RMSE) of individual deviations was about $30 \mu \mathrm{g} \mathrm{m}^{-3}$. In contrast, the $\mathrm{NH}_{3}$ concentrations calculated from the bLS/FTIR emissions showed generally larger deviations from the measured impinger concentrations (Fig. 9, panel b). There were systematic differences into opposite directions in the two events. In addition, the inconsistency found between the three FTIR measurement heights is clearly visible again. On 4 August, the concentrations obtained from the lowest height deviated most from the reference with the reverse picture on 6 August, when the uppermost height produced emissions least corresponding to the impinger measurements. Using bLS/FTIR emissions, the impinger concentrations were systematically overestimated by $23 \%$ to $43 \%$ on 4 August and underestimated by $10 \%$ to $23 \%$ on 6 August (Table 5).

Concerning EC measurements, the high-frequency attenuation of fast $\mathrm{NH}_{3}$ fluctuations inside the sampling and analytical system causes systematic under-determination of the fluxes. We corrected the EC fluxes for this amount as described by Sintermann et al. (2011). As this is an empirical approach comparing the ogives of the $\mathrm{NH}_{3}$ fluxes to those of sensible heat fluxes, an incomplete correction cannot principally be ruled out. To provide an additional check, the EC/HT-CIMS derived emissions were also used to calculate the concentrations at the HT-CIMS location via bLS. These were compared to the $\mathrm{NH}_{3}$ concentrations measured by HTCIMS averaged over $10 \mathrm{~min}$ and one hour intervals, sufficiently long to exclude damping influences. Figure 10 shows that there was good agreement on both days.

\subsubsection{Plausibility of initial volatilisation}

A physical-chemical upper limit of the initial $\mathrm{NH}_{3}$ volatilisation, expressed as $F_{\text {ini }}$, was derived from the slurry analysis and meteorological properties as described in Sect. 2.4. There was a considerable range of $F_{\text {ini }}$ calculated from the slurry analysis (Table 3 ), mainly because of limited analytical precision in $\mathrm{pH}$ determination (Table 2). While the initial 

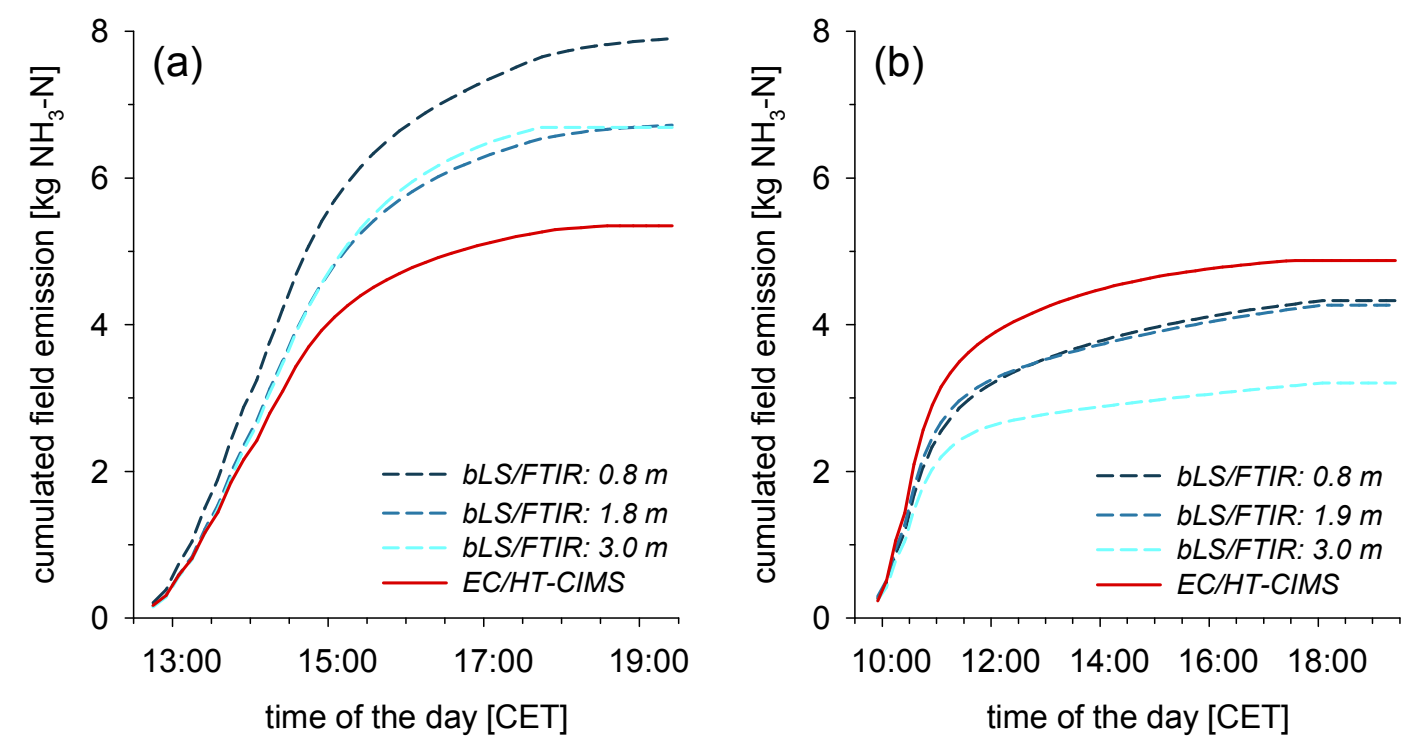

Fig. 8. Cumulative field emissions derived from EC/HT-CIMS and bLS/FTIR on (a) 4 August 2009 and (b) 6 August 2009.
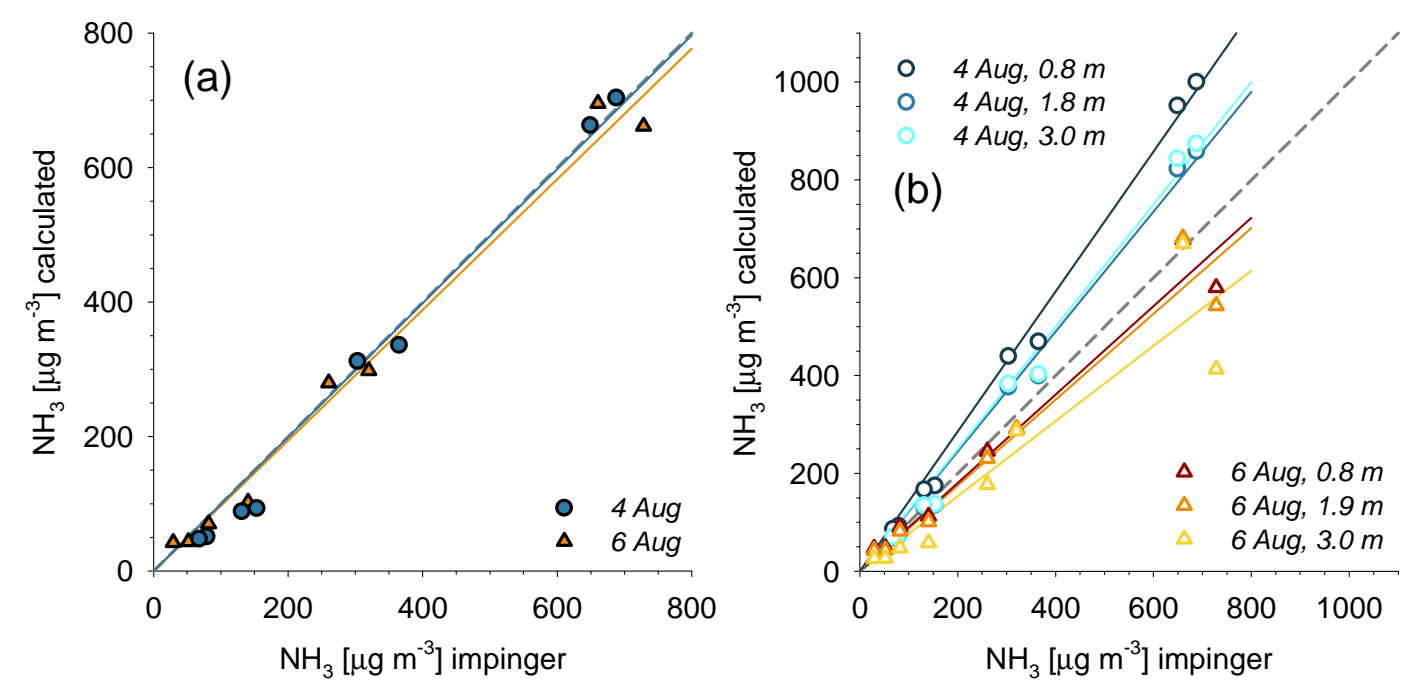

Fig. 9. Comparison of $\mathrm{NH}_{3}$ concentrations measured by impingers and calculated with bLS, using (a) $F_{\text {volat,EC }}$ and (b) $F_{\text {volat,FTIR }}$; dashed lines show 1:1 relationship and solid lines depict linear regressions through zero (regression parameters see Table 5). 
Table 4. Cumulated field emissions calculated by EC/HT-CIMS and by bLS/FTIR on (I) lower, (II) middle and (III) upper measurement height.

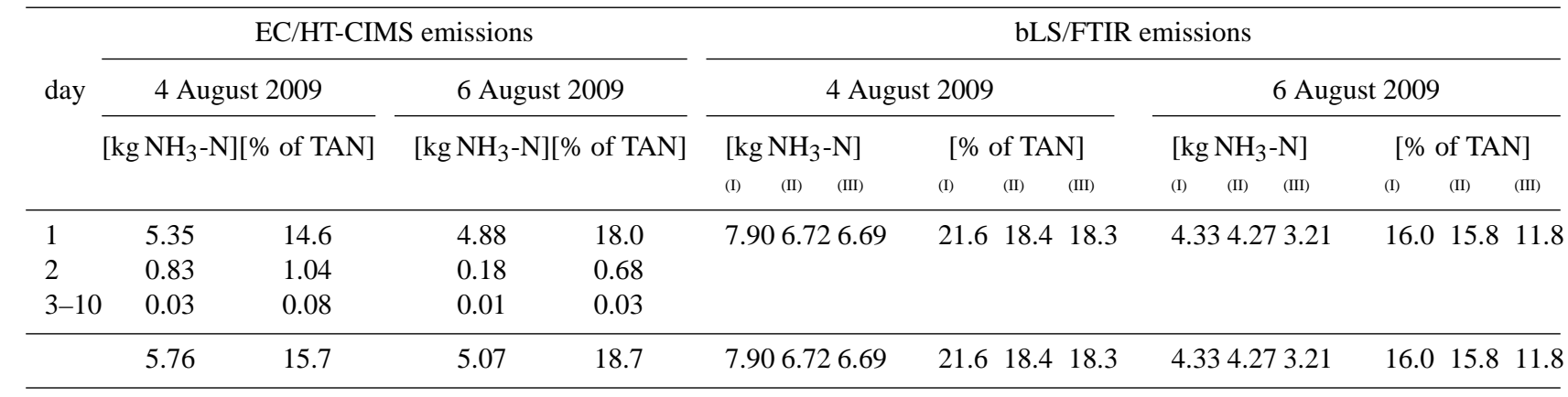

Table 5. Parameters of linear regressions of $\mathrm{NH}_{3}$ concentrations measured by impingers and corresponding concentrations calculated with bLS, using the emissions $F_{\text {volat }}$ derived from the respective methods (Fig. 9); RMSE = root mean squared error (in $\mu \mathrm{g} \mathrm{m}^{-3}$ ).

\begin{tabular}{|c|c|c|c|c|c|c|c|c|c|c|c|c|}
\hline & \multicolumn{3}{|c|}{ EC/HT-CIMS } & \multicolumn{3}{|c|}{$\mathrm{bLS} / \mathrm{FTIR}_{\text {low }}$} & \multicolumn{3}{|c|}{ bLS/FTIR middle $_{\text {}}$} & \multicolumn{3}{|c|}{${\mathrm{bLS} / \mathrm{FTIR}_{\text {high }}}_{\text {}}$} \\
\hline & slope & $R^{2}$ & RMSE & slope & $R^{2}$ & RMSE & slope & $R^{2}$ & RMSE & slope & $R^{2}$ & RMSE \\
\hline 4 August 2009 & 1.00 & 0.985 & 31.2 & 1.43 & 0.993 & 28.4 & 1.23 & 0.990 & 31.0 & 1.25 & 0.989 & 32.8 \\
\hline 6 August 2009 & 0.97 & 0.985 & 30.4 & 0.90 & 0.967 & 41.4 & 0.88 & 0.950 & 50.8 & 0.77 & 0.859 & 81.3 \\
\hline
\end{tabular}

fluxes derived from the flux determination of all field-applied systems were below the maximum possible values on $4 \mathrm{Au}-$ gust, the values on 6 August were in range suggesting that the inferred initial fluxes had been close to the theoretical maximum.

\section{Discussion}

\subsection{Uncertainty of the EC/HT-CIMS approach}

The largest difficulty and strongest potential limitation of the EC approach for $\mathrm{NH}_{3}$ is the correct quantification of the attenuation of fast and turbulent high-frequent concentration fluctuations between the sample location and actual measurement (Brodeur et al., 2009). To our knowledge, the only other study of $\mathrm{NH}_{3} \mathrm{EC}$ flux measurements that simultaneously compared the results to the fluxes obtained from an established (gradient) method discovered substantial high-frequency attenuation losses that could not be quantified by inherent methods (Whitehead et al., 2008). Sintermann et al. (2011) quantified the attenuation empirically and corrected the raw EC fluxes for high-frequency losses. Figure 10 demonstrates that the EC derived emissions $F_{\text {volat,EC }}$ were consistent with $\mathrm{NH}_{3}$ concentrations recorded by the HT-CIMS, averaged over timescales when high-frequency attenuation is considered not to play a role. As well, the comparison to the measured impinger concentrations was good.
This underlines that the applied correction was appropriate and systematic underestimation of the fluxes due to highfrequency attenuation could be avoided.

Analytical difficulties in $\mathrm{NH}_{3}$ measurements may originate from gas-phase calibration uncertainties (von Bobrutzki et al., 2010), drifting instrumental stability (Milford et al., 2009), selective sampling and analysis of gas and aerosol phase and $\mathrm{NH}_{3}$ sorption in filters, tubes and devices (Parrish and Fehsenfeld, 2000). Flux measurements with the aerodynamic gradient method using AMANDA instruments are associated with uncertainties of $20 \%$ to $76 \%$ (Sutton et al., 2000; Milford et al., 2009). After fertilisation, relaxed eddy accumulation approaches have underestimated $\mathrm{NH}_{3}$ fluxes compared to the AMANDA gradient systems by $20 \%$ to $70 \%$ (Hensen et al., 2009) while EC measurements based on laser absorption spectrometry have exhibited biases in the order of $-50 \%$ when related to the AMANDA fluxes (Whitehead et al., 2008). Emissions from field application of organic fertiliser determined with simultaneously replicated mass balance measurements using passive flux samplers (Leuning et al., 1985) showed unexplained variations between $23 \%$ to $52 \%$ (Misselbrook et al., 2005b). Considering these differences as representative for the range of expected uncertainties in $\mathrm{NH}_{3}$ flux measurements, the consistency between EC/HT-CIMS derived emissions and the impinger concentrations, found here, is excellent. 


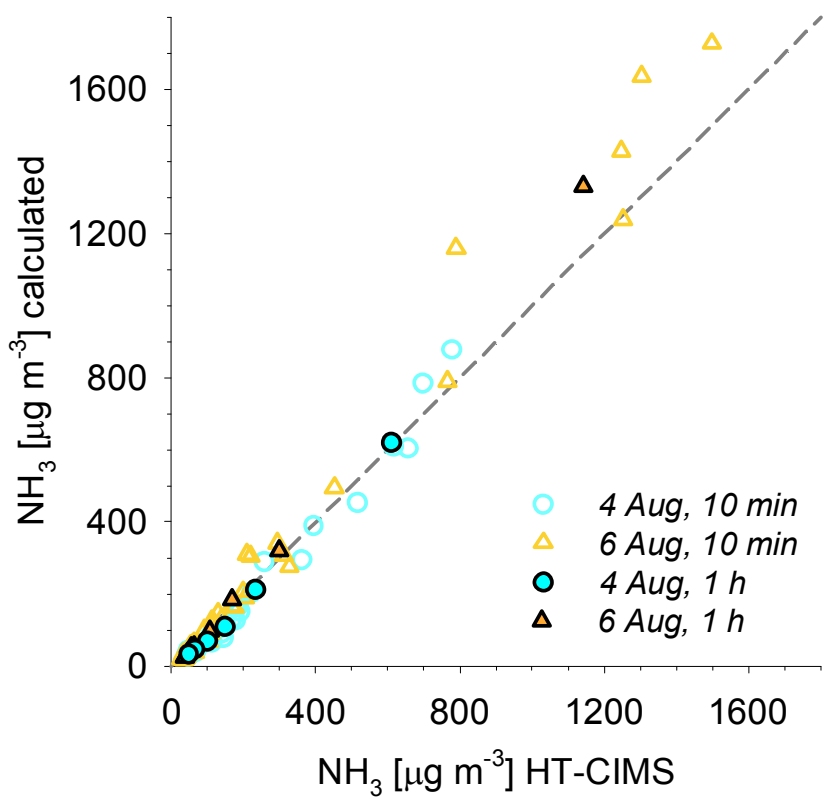

Fig. 10. Measured HT-CIMS $\mathrm{NH}_{3}$ concentrations (averaged over $10 \mathrm{~min}$ and $1 \mathrm{~h}$ ) vs. corresponding concentrations calculated by bLS using $F_{\text {volat,EC }}$; dashed line shows 1:1 relationship.

\subsection{Uncertainty of the bLS/FTIR approach}

Inspection of the bLS/FTIR emissions revealed two distinct features: deviations between the results derived from the three measurement heights within one fertilisation event (Figs. 7, 8, and 9) and, when compared to the impinger concentrations and EC/HT-CIMS results, an apparent overestimation on 4 August and an underestimation on 6 August (Fig. 9; Table 5). The relative deviation with respect to the impinger concentrations were around $+24 \%$ (best two measurement heights) and $+43 \%$ (least suitable measurement height) for the cropland fertilisation and around $-11 \%$ (best two measurement heights) to $-23 \%$ for the grassland fertilisation. These values are within the typical uncertainty range of $\mathrm{NH}_{3}$ flux determination as reviewed above.

In the past years the applied bLS method has been proven to determine emissions from concentration measurements with accuracies around 10\% under most circumstances (Flesch et al., 2004, 2005; McBain and Desjardins, 2005; Gao et al., 2009a, 2010). It is considered to be currently among the most accurate micrometeorological techniques to calculate dispersion and determine emission rates (Denmead, 2008; Laubach, 2010; Loubet et al., 2010). It has been applied to assess methane and/or $\mathrm{NH}_{3}$ emissions from agricultural fields fertilised with slurry (Sanz et al., 2010) and urea (Sommer et al., 2005), grazed fields (Denmead et al., 2004; Laubach and Kelliher, 2005; Laubach et al., 2008; Laubach, 2010), cattle feedlots (Flesch et al., 2007; McGinn et al., 2007; van Haarlem et al., 2008; Loh et al., 2008), and even complete farms (Flesch et al., 2009). The bLS calcu- lates emissions accurately provided homogeneously emitting source areas (or well represented point sources), a precise monitoring of $c_{\mathrm{bgd}}$ and a largely undisturbed wind field, i.e. an obstacle-free downwind fetch longer than 5-10 (Flesch et al., 2005; Gao et al., 2010) to 25 (McBain and Desjardins, 2005) times $z-d$, depending of the complexity of the disturbance. The accuracy can be negatively affected by extreme atmospheric instability and is sensitive to low $U$ and nonstationarity indicated by low $u_{*}$ (Flesch et al., 2004; McBain and Desjardins, 2005; Gao et al., 2009b). In the present study, all mentioned quality criteria were fulfilled. The differences in bLS/FTIR emission estimates depending on measurement height (Figs. 7 and 9) may be explained by another specific limitation of the model. Laubach (2010) found that the accuracy of the bLS, implemented in WindTrax, can depend on the ratio of $z-d$ to the mean fetch length with resulting differences of up to $20 \%$ under unfavourable conditions. This is probably due to an overestimation of the speed of vertical dispersion as it relates on the uncertain parameterisation of energy dissipation. Laubach (2010) identified a specific relative crossover height $(z-d /$ mean fetch length) at which the effect vanishes. Below, potential overestimation occurs, reversing into underestimation above. It was not possible to identify a representative crossover height in the present study as this would have required winds blowing perpendicular to the FTIR paths in order to determine the mean fetch length. It is, however, very likely that on 4 August the lowest FTIR height was significantly below the crossover height due to the orientation of the field setup relative to the predominant wind direction. This could qualitatively explain the overestimation of the emissions derived from the lowest height relative to the other heights. The reverse picture occurred on 6 August when probably the highest measurement height exceeded the respective crossover height. This was the case because the emission fetch for the measurement was quite small that day, as the relative influence of source areas outside the fertilised field (due to easterly wind components) were larger for the short FTIR path on that day, producing a smaller effective fetch for the line concentration measuruement (see Fig. 1). Taking these aspects into consideration, it is likely that the respective single outliers of the bLS/FTIR emissions were an effect of the shifting bLS performance due to the experimental setting. In addition, on 6 August the wind direction fluctuated significantly and thus the angle of the FTIR paths often happened to be close to the direction of the wind which can increase the uncertainty in the emission calculation (Flesch et al., 2004). The preceding reflections suggest that within one event, differentiating between the three measurement heights, the two bLS/FTIR emissions showing agreement were more plausible than the deviating value. The different biases observed in the two fertilisation events might be attributed to shifting instrumental performance. For example, in a recent intercomparison, von Bobrutzki et al. (2010) characterised eleven state-of-the-art instruments for $\mathrm{NH}_{3}$ concentration measurements based on 
eight analytical methods. Agreements better than $25 \%$ can hardly be achieved and deviations can be much larger.

\subsection{Dynamics of $\mathrm{NH}_{3}$ volatilisation}

The fluxes presented in our study show that highest emissions from individual tracks occurred immediately after slurry application. It is difficult to assess the emission course over the first minutes after the spreading. The determination of the function parameters relied on $10 \mathrm{~min}$ averages and Eq. (2) allowed to extrapolate to the beginning of fertilisation. The spreading of the slurry itself took about $3 \mathrm{~min}$, thus the initial timing was not sharply defined. On 4 August, there was a data gap of about $20 \mathrm{~min}$ in the HT-CIMS measurements at the beginning of the fertilisation introducing additional uncertainty into the back-extrapolation.

According to Sommer et al. (2003) there are two distinct stages in the $\mathrm{NH}_{3}$ volatilisation which could explain a biexponential decrease. In the first period, immediately after fertilisation, the slurry is exposed at the soil/vegetationatmosphere interface as it has not undergone complete soil infiltration and drying. The emissions depend only on the characteristics of the slurry on the surface and of the atmospheric transport. At the second stage, the emissions are governed by slurry-soil interactions. They include evaporation, sorption and microbial activity provoking a time course that exhibits lowered emissions with a longer time constant. Considering the first stage, an upper limit of the initial volatilisation rate can be calculated from the slurry and atmospheric properties. Volatilisation of fatty acids as well as fast mineralisation with carbon dioxide volatilisation can increase the slurry pH (Vandre and Clemens, 1997) promoting high emissions. On the other hand, volatilisation of $\mathrm{NH}_{3}$ decreases $\mathrm{pH}$ (Sommer et al., 2003). In slurry, a temporal increase in $\mathrm{pH}$ has been observed with a high total inorganic carbon (TIC) content of the slurry (Sommer and Sherlock, 1996). We have no information about TIC in the applied slurry, but since it was rather thin (low DM content, most of the $\mathrm{N}$ in form of TAN: $81 \%$ and $75 \%$, respectively) and as infiltration happened fast we must assume that a change in slurry $\mathrm{pH}$ was not driving $\mathrm{NH}_{3}$ volatilisation in our experiment. On 6 August the slurry was applied to the cut grassland where the canopy intercepted a larger fraction of the slurry exposing more liquid to direct volatilisation. The emission enhancing effect of slurry interception on a short canopy was shown by Rochette et al. (2008) and Thorman et al. (2008). Therefore, emissions in the initial period can be expected to peak stronger on grassland than on harvested arable land. It has been demonstrated that increasing DM content dampens initial $\mathrm{NH}_{3}$ emissions but prolongs them in the following (Braschkat et al., 1997). The slurry spread in our experiments generally had a low DM content and thus promoted quick volatilisation as reflected in the fast initial decrease of the emissions. Increased wind speed and air temperatures as well enhance initial emissions (Søgaard et al., 2002), and in the experiments wind speed and especially the high air temperatures (though in a slightly different combination between the two events) favoured a high emission rate during the initial period following fertilisation (Sommer et al., 1991). Considering the high infiltration and sorption potential of the applied slurry with the bare soil on 4 August (see below), it is likely that equilibrium in $\mathrm{NH}_{3}$ volatilisation described by Henry's law did not occur over an initial period of several minutes during that event. Consequently, the initial flux derived from the bi-exponential fit was lower than the potential flux derived from slurry properties, surface temperature and transfer velocity. On $6 \mathrm{Au}-$ gust, the initial $\mathrm{NH}_{3}$ volatilisation as determined from the slurry properties matched the initial values identified by the field measurements (Sect. 3.4.2). The stronger slurry-canopy interception and thus slower soil infiltration during this experiment favoured slurry-atmosphere equilibrium conditions. We conclude therefore that the initial emissions inferred from the field measurements were not prone to severe underestimation as they were close to a physical-chemical plausible value. Employing the Henry equilibrium like in Eq. (6) to calculate $c\left(z_{0}^{\prime}\right)$ ignores the fact that slurry is not really an ideal solution. The activity of other dissolved ions can influence the ionic strength of the slurry solution which may decrease the expected volatilisation. When considering the applied rather thin slurry to have an ionic strength at the higher end of the average range reported in the literature, the volatilisation would be reduced by about one quarter (Sommer et al., 2003) and the main findings summarised in Table 3 would not very much change. It becomes only more obvious that $F_{\text {ini }}$ derived from the various measurement systems were very close to the maximum on 6 August.

The soil at the Oensingen site has a cation exchange capacity of more than $20 \mathrm{cmol} \mathrm{kg}^{-1}$. Compared to the grassland, the arable field's sorption potential of the soil acts more effectively in buffering emissions from the low DM containing slurry since bare, dry soil without canopy interception promotes fast penetration below the surface (Sommer and Jacobsen, 1999; Sommer and Hutchings, 2001; Misselbrook et al., 2005c; Sommer et al., 2006). In addition, slurry TAN content drives to a large extent the $\mathrm{NH}_{3}$ emissions (Menzi et al., 1998). The applied slurry on 6 August had a higher TAN and DM content (albeit a lower $\mathrm{pH}$ ) than on 4 August. Therefore, the emissions could be expected to be higher on 6 August relative to the event on 4 August (Sommer and Olesen, 1991; Braschkat et al., 1997; Søgaard et al., 2002; Sommer et al., 2003) when they declined with a less pronounced bi-exponential course.

It is known for the investigated site that the emissions decrease exponentially over only a few days after slurry spreading. The vast majority of $\mathrm{NH}_{3}$ loss (at least $80 \%$ of the total emission) has always been observed at the day of fertilisation (Spirig et al., 2010). Such a course with the main part of emissions occurring in the first ten to twenty hours is quite common after slurry spreading and has often been documented (e.g. Pain et al., 1989; Mannheim et al., 1995; 
Braschkat et al., 1997; Vandre et al., 1997; Génermont et al., 1998; Menzi et al., 1998; Misselbrook et al., 2002; Huijsmans et al., 2003; Rochette et al., 2008; Sanz et al., 2010). The conditions at the Oensingen grassland revert back to a small, potentially bi-directional flux regime after about 5 days and even the canopy compensation point returns to prefertilisation levels after about 10 days (Flechard et al., 2010).

\section{Conclusions}

Field scale $\mathrm{NH}_{3}$ emissions from slurry application were determined over a cropland and a grassland field by two different analytical approaches. For both methods, the respective detailed footprint analysis in combination with the high time resolution of $10 \mathrm{~min}$ averages enabled to attribute the measured fluxes and concentrations, respectively, to individual slurry track emissions. In this way, the very important initial period of emissions could be described in detail.

The cumulated EC/HT-CIMS and (the two most plausible) bLS/FTIR emissions agreed within $20 \%$, a difference typical for $\mathrm{NH}_{3}$ flux quantification. Both methods were further tested for consistency with independent impinger concentration measurements. These analyses showed good agreement without systmatic deviations for the EC/HT-CIMS results (uncertainty $\pm 8 \%$ ) but some systematic over- or underestimation for the bLS/FTIR results. Therefore we attribute the observed differences between the two flux methods mainly to uncertainties of bLS/FTIR. The overall $\mathrm{NH}_{3}$ loss (EC/HTCIMS) during the day of slurry spreading was quantified to amount for $14.6 \%$ of the applied TAN at the cropland and $18.0 \%$ at the grassland with contributions $\leq 1 \%$ loss of TAN on the subsequent day.

Over two years, Spirig et al. (2010) determined $\mathrm{NH}_{3}$ emissions following slurry application at the Oensingen grassland field using wet chemical AiRRmonia instruments (Erisman et al., 2001) in a gradient approach. They had to estimate the initial phase's (first one to four hours) field emissions due to limited resolution of the instruments and the unsteady, inhomogeneous emission conditions associated with slurry spreading, concluding their overall flux uncertainty was dominated by the vagueness of this period. The approaches and resulting emissions in the present study now provide a clearer, less uncertain picture over the whole period of field emissions yielding similar losses as described by Spirig et al. (2010). Over three years, seasonally distributed between April and October, the grassland field's slurry $\mathrm{NH}_{3}$ emissions have been quantified in total by means of four different approaches. They kept persistently small in a range between about $4 \%$ and $19 \%$ of the applied TAN.

Generally, flux measurements on the field scale under realistic slurry spreading practice are only feasible with techniques that provide a fast flux determination and can measure a large dynamic concentration range with sufficient accuracy. These requirements were particularly met with the two meth- ods applied in the present study, having the advantage that analytics were either based on open path measurements or were applied with excess heating of all inner walls minimising damping effects and including procedures for quantifying the influence of the remaining wall interactions on the flux. For both methods applied here, the analytical instruments are relatively expensive and need a high level of maintenance in the field. Thus, an important future challenge will be to establish either of the two methods with easier-to-use (and cheaper) analytical instruments. For the bLS method, also point concentration measurements instead of open-path line measurements could be used. However, a high temporal resolution (about $15 \mathrm{~min}$ or better) is necessary for properly evaluating the temporal dynamics. Another important future challenge will be the modelling of the observed course of fluxes with a mechanistic approach and to validate such a model at differing site conditions.

Acknowledgements. For funding our work we gratefully thank the Swiss National Science Foundation (TERMS, 200021-117686/1) and the EU project NitroEurope (Contract 017841) that is funded under the EC 6th Framework Programme for Research and Technological Development. As well, the research leading to these results has received funding from the [EU] Seventh Framework Programme ([FP7/2007-2013] under grant agreement $n^{\circ}$ [PIEFGA-2008-220842]). The Swiss Federal Office for the Environment and the Swiss Federal Office for Agriculture have financially supported the field experiment. We are very grateful to Kerstin Zeyer and Lukas Emmenegger from the Swiss Federal Laboratories for Materials Science and Technology (EMPA) who provided the in-field calibration device and the cavity ring-down spectroscopy measurements. We would also like to thank the farmer Walter Ingold for all his cooperation as well as Markus Jocher from our group for his support.

Edited by: F. X. Meixner

\section{References}

Ammann, C., Brunner, A., Spirig, C., and Neftel, A.: Technical note: Water vapour concentration and flux measurements with PTR-MS, Atmos. Chem. Phys., 6, 4643-4651, doi:10.5194/acp6-4643-2006, 2006.

Ammann, C., Spirig, C., Leifeld, J., and Neftel, A.: Assessment of the nitrogen and carbon budget of two managed temperate grassland fields, Agr. Ecosyst. Environ., 133, 150-162, 2009.

Aneja, V. P., Schlesinger, W. H., and Erisman, J. W.: Farming pollution, Nat. Geosci., 1, 409-411, 2008.

Berden, G., Peeters, R., and Meijer, G.: Cavity ring-down spectroscopy: Experimental schemes and applications, Int. Revs. in Phys. Chem., 19, 565-607, doi:10.1080/014423500750040627, 2000.

Bleeker, A., Sutton, M. A., Acherman, B., Alebic-Juretic, A., Aneja, V. P., Ellermann, T., Erisman, J. W., Fowler, D., Fagerli, H., Gauger, T., Harlen, K. S., Hole, L. R., Horvath, L., Mitosinkova, M., Smith, R. I., Tang, Y. S., and van Pul, A.: Linking Ammonia Emission Trends to Measured Concentrations and 
Deposition of Reduced Nitrogen at Different Scales, in: Atmospheric Ammonia - detecting emission changes and environmental impacts, edited by: Sutton, M. A., Reis, S., and Baker, S. M. H., 123-180, Springer, 2009.

Braschkat, J., Mannheim, T., and Marschner, H.: Estimation of ammonia losses after application of liquid cattle manure on grassland, Z. Pflanz. Bodenkunde, 160, 117-123, 1997.

Brodeur, J. J., Warland, J. S., Staebler, R. M., and WagnerRiddle, C.: Technical note: Laboratory evaluation of a tunable diode laser system for eddy covariance measurements of ammonia flux, Agr. Forest Meteorol., 149, 385-391, doi:10.1016/j.agrformet.2008.08.009, 2009.

Dabberdt, W. F., Lenschow, D. H., Horst, T. W., Zimmermann, P. R., Oncley, S. P., and Delany, A. C.: Atmosphere-surface exchange measurements, Science, 260, 1472-1481, 1993.

Denmead, O. T.: Approaches to measuring fluxes of methane and nitrous oxide between landscapes and the atmosphere, Plant. Soil, 309, 5-24, doi:10.1007/s11104-008-9599-z, 2008.

Denmead, O. T., Simpson, J. R., and Freney, J. R.: Direct field measurement of ammonia emission after injection of anhydrous ammonia, Soil Sci. Soc. Am. J., 41, 1001-1004, 1977.

Denmead, O. T., Chen, D., Turner, D., Li, Y., and Edis, R.: Micrometeorological measurements of ammonia emissions during phases of the grazing rotation of irrigated dairy pastures, in: Proc. of Supersoil 2004: Program and Abstracts for the 3rd Australian New Zealand Soils Conference, 5-9 December 2004, University of Sydney, Sidney, Australia, 2004.

EEA: EMEP/EEA emission inventory guidebook 2009, European Environment Agency, Office for Official Publications of the European Communities, Luxembourg, http://www.eea.europa. eu/publications/emep-eea-emission-inventory-guidebook-2009, 2009

Erisman, J. W., Otjes, R., Hensen, A., Jongejan, P., van den Bulk, P., Khlystov, A., Mols, H., and Slanina, S.: Instrument development and application in studies and monitoring of ambient ammonia, Atmos. Environ., 35, 1913-1922, 2001.

Erisman, J. W., Bleeker, A., Galloway, J., and Sutton, M. S.: Reduced nitrogen in ecology and the environment, Environ. Pollut., 150, 140-149, doi:10.1016/j.envpol.2007.06.033, 2007.

Erisman, J. W., Bleeker, A., Hensen, A., and Vermeulen, A.: Agricultural air quality in Europe and the future perspectives, Atmos. Environ., 42, 3209-3217, doi:10.1016/j.atmosenv.2007.04.004, 2008.

Erisman, J. W., Bleeker, A., Neftel, A., Aneja, V., Hutchings, N., Kinsella, L., Tang, Y. S., Webb, J., Sponar, M., Raes, C., Mitosinkova, M., Vidic, S., Andersen, H. V., Klimont, Z., Pinder, R., Baker, S., Reidy, B., Flechard, C., Horvath, L., Lewandowska, A., Gillespie, C., Wallasch, M., Gehrig, R., and Ellerman, T.: Detecting Change in Atmospheric Ammonia Following Emission Changes, in: Atmospheric Ammonia - detecting emission changes and environmental impacts, edited by: Sutton, M. A., Reis, S., and Baker, S. M. H., 383-390, Springer, 2009.

FAO, ISRIC, and ISSS: World reference base for soil resources, World soil resources reports, 84, Food and Agriculture Organization of the United Nations, Rome, 1998.

Flechard, C. R., Spirig, C., Neftel, A., and Ammann, C.: The annual ammonia budget of fertilised cut grassland - Part 2: Seasonal variations and compensation point modeling, Biogeosciences, 7 ,
537-556, doi:10.5194/bg-7-537-2010, 2010.

Flechard, C. R., Nemitz, E., Smith, R. I., Fowler, D., Vermeulen, A. T., Bleeker, A., Erisman, J. W., Simpson, D., Zhang, L., Tang, Y. S., and Sutton, M. A.: Dry deposition of reactive nitrogen to European ecosystems: a comparison of inferential models across the NitroEurope network, Atmos. Chem. Phys., 11, 2703-2728, doi:10.5194/acp-11-2703-2011, 2011.

Flesch, T. K., Wilson, J. D., and Yee, E.: Backward-time lagrangian stochastic dispersion models and their application to estimate gaseous emissions, J. Appl. Meteorol., 34, 1320-1332, 1995.

Flesch, T. K., Wilson, J. D., Harper, L. A., Crenna, B. P., and Sharpe, R. R.: Deducing ground-to-air emissions from observed trace gas concentrations: A field trial, J. Appl. Meteorol., 43, 487-502, 2004.

Flesch, T. K., Wilson, J. D., Harper, L. A., and Crenna, B. P.: Estimating gas emissions from a farm with an inverse-dispersion technique, Atmos. Environ., 39, 4863-4874, doi:10.1016/j.atmosenv.2005.04.032, 2005.

Flesch, T. K., Wilson, J. D., Harper, L. A., Todd, R. W., and Cole, N. A.: Determining ammonia emissions from a cattle feedlot with an inverse dispersion technique, Agr. Forest Meteorol., 144, 139-155, doi:10.1016/j.agrformet.2007.02.006, 2007.

Flesch, T. K., Harper, L. A., Powell, J. A., and Wilson, J. D.: Inverse-dispersion calculation of ammonia emissions from Wisconsin dairy farms, T. ASABE, 52, 253-265, 2009.

Foken, T. and Wichura, B.: Tools for quality assessment of surfacebased flux measurements, Agr. Forest Meteorol., 78, 83-105, 1996.

Fowler, D. and Duyzer, J.: Micrometeorological techniques for the measurement of trace gas-exchange, in: Exchange of trace gases between terrestrial ecosystems and the atmosphere, edited by: Andreae, M. O. and Schimel, D. S., vol. 47 of Life Sciences Research Report, 189-207, John Wiley \& Sons ltd, 1989.

Galloway, J. N., Aber, J. D., Erisman, J. W., Seitzinger, S. P., Howarth, R. W., Cowling, E. B., and Cosby, B. J.: The nitrogen cascade, BioScience, 53, 341-356, 2003.

Gao, Z., Desjardins, R. L., and Flesch, T. K.: Comparison of a simplified micrometeorological mass difference technique and an inverse dispersion technique for estimating methane emissions from small area sources, Agr. Forest Meteorol., 149, 891-898, doi:10.1016/j.agrformet.2008.11.005, 2009a.

Gao, Z., Mauder, M., Desjardins, R. L., Flesch, T. K., and van Haarlem, R. P.: Assessment of the backward Lagrangian Stochastic dispersion technique for continuous measurements of CH4 emissions, Agr. Forest Meteorol., 149, 1516-1523, doi:10.1016/j.agrformet.2009.04.004, 2009b.

Gao, Z., Desjardins, R. L., and Flesch, T. K.: Assessment of the uncertainty of using an inverse-dispersion technique to measure methane emissions from animals in a barn and in a small pen, Atmos. Environ., 44, 3128-3134, doi:10.1016/j.atmosenv.2010.05.032, 2010.

Gärtner, A., Hirschberger, R., and Kotzian, F.: Estimation of diffuse ammonia emissions during and after slurry spreading, Gefahrst. Reinhalt. L., 68, 149-155, 2008.

Génermont, S., Cellier, P., Flura, D., Morvan, T., and Laville, P.: Measuring ammonia fluxes after slurry spreading under actual field conditions, Atmos. Environ., 32, 279-284, 1998.

Hansel, A., Jordan, A., Holzinger, R., Prazeller, P., Vogel, W., and Lindinger, W.: Proton-Transfer Reaction Mass-Spectrometry - 
Online trace gas-analysis at the ppb level, Int. J. Mass Spectrom., 149, 609-619, 1995.

Heise, H. M., Müller, U., Gärtner, A. G., and Hölscher, N.: Improved chemometric strategies for quantitative FTIR spectral analysis and applications in atmospheric open-path monitoring, Field Anal. Chem. Tech., 5, 13-28, 2001.

Hensen, A., Nemitz, E., Flynn, M. J., Blatter, A., Jones, S. K., Srensen, L. L., Hensen, B., Pryor, S. C., Jensen, B., Otjes, R. P., Cobussen, J., Loubet, B., Erisman, J. W., Gallagher, M. W., Neftel, A., and Sutton, M. A.: Inter-comparison of ammonia fluxes obtained using the Relaxed Eddy Accumulation technique, Biogeosciences, 6, 2575-2588, doi:10.5194/bg-6-2575-2009, 2009.

Hirschberger, R.: Automotive emission analysis with spectroscopic techniques, in: Encyclopedia of Analytical Chemistry, edited by: Meyers, R. A., 3, 1914-1936, John Wiley \& Sons, Chichester, 2000.

Huijsmans, J. F. M., Hol, J. M. G., and Hendriks, M. M. W.: Effect of application technique, manure characteristics, weather and field conditions on ammonia volatilization from manure applied to grassland, Neth. J. Agr. Sci., 49, 323-342, 2001.

Huijsmans, J. F. M., Hol, J. M. G., and Vermeulen, G. D.: Effect of application method, manure characteristics, weather and field conditions on ammonia volatilization from manure applied to arable land, Atmos. Environ., 37, 3669-3680, doi:10.1016/S1352-2310(03)00450-3, 2003.

Kljun, N., Kormann, R., Rotach, M. W., and Meixer, F. X.: Comparison of the Langrangian footprint model LPDM-B with an analytical footprint model, Bound.-Lay. Meteorol., 106, 349-355, 2003.

Kormann, R. and Meixner, F. X.: An analytical footprint model for non-neutral stratification, Bound.-Lay. Meteorol., 99, 207-224, 2001.

Laubach, J.: Testing of a Lagrangian model of dispersion in the surface layer with cattle methane emissions, Agr. Forest Meteorol., 150, 1428-1442, doi:10.1016/j.agrformet.2010.07.006, 2010.

Laubach, J. and Kelliher, F. M.: Measuring methane emission rates of a dairy cow herd (II): results from a backwardLagrangian stochastic model, Agr. Forest Meteorol., 129, 137150, doi:10.1016/j.agrformet.2004.12.005, 2005.

Laubach, J., Kelliher, F. M., Knight, T. W., Clark, H., Molano, G., and Cavanagh, A.: Methane emissions from beef cattle a comparison of paddock-and animal-scale measurements, Aust. J. Exp. Agr., 48, 132-137, doi:10.1071/EA07256, 2008.

Leuning, R., Freney, J. R., Denmead, O. T., and Simpson, J. R.: A sampler for measuring atmospheric ammonia flux, Atmos. Environ., 19, 1117-1124, 1985.

Lindinger, W., Hansel, A., and Jordan, A.: On-line monitoring of volatile organic compounds at pptv levels by means of protontransfer-reaction mass spectrometry (PTR-MS) - Medical applications, food control and environmental research, Int. J. Mass Spectrom., 173, 191-241, 1998.

Loh, Z., Chen, D., Bai, M., Naylor, T., Griffith, D., Hill, J., Denmead, T., McGinn, S., and Edis, R.: Measurement of greenhouse gas emissions from Australian feedlot beef production using open-path spectroscopy and atmospheric dispersion modelling, Aust. J. Exp. Agr., 48, 244-247, doi:10.1071/EA07244, 2008.

Loubet, B., Milford, C., Hensen, A., Daemmgen, U., Erisman, J.W., Cellier, P., and Sutton, M. A.: Advection of $\mathrm{NH}_{3}$ over a pasture field and its effect on gradient flux measurements, Biogeosciences, 6, 1295-1309, doi:10.5194/bg-6-1295-2009, 2009.

Loubet, B., Génermont, S., Ferrara, R., Bedos, G., Decuq, G., Personne, E., Fanucci, O., Durand, B., Rana, G., and Cellier, P.: An inverse model to estimate ammonia emissions from fields, Eur. J. Soil Sci., 61, 793-805, doi:10.1111/j.1365-2389.2010.01268.x, 2010.

Mannheim, T., Braschkat, J., and Marschner, H.: Measurement of ammonia emission after liquid manure application: II. Comparison of the wind tunnel and the IHF method under field conditions, Z. Pflanz. Bodenkunde, 158, 215-219, 1995.

McBain, M. C. and Desjardins, R. L.: The evaluation of a backward Lagrangian stochastic (bLS) model to estimate greenhouse gas emissions from agricultural sources using a synthetic tracer source, Agr. Forest Meteorol., 135, 61-72, doi:10.1016/j.agrformet.2005.10.003, 2005.

McGinn, S. M., Flesch, T. K., Crenna, B. P., Beauchernin, K. A., and Coates, T.: Quantifying ammonia emissions from a cattle feedlot using a dispersion model, J. Environ. Qual., 36, 15851590, 2007.

Menzi, H., Katz, P. E., Fahrni, M., Neftel, A., and Frick, R.: A simple empirical model based on regression analysis to estimate ammonia emissions after manure application, Atmos. Environ., 32, 301-307, 1998.

Milford, C., Theobald, M. R., Nemitz, E., Hargreaves, K. J., Horvath, L., Raso, J., Dämmgen, U., Neftel, A., Jones, S. K., Hensen, A., Loubet, B., Cellier, P., and Sutton, M. A.: Ammonia fluxes in relation to cutting and fertilization of an intensively managed grassland derived from an inter-comparison of gradient measurements, Biogeosciences, 6, 819-834, doi:10.5194/bg-6819-2009, 2009.

Misselbrook, T. H., Smith, K. A., Johnson, R. A., and Pain, B. F.: Slurry application techniques to reduce ammonia emissions: Results of some UK field-scale experiments, Biosyst. Eng., 81, 313-321, doi:10.1006/bioe.2001.0017, 2002.

Misselbrook, T. H., Nicholson, F. A., and Chambers, B. J.: Predicting ammonia losses following the application of livestock manure to land, Bioresource Technol., 96, 159-168, doi:10.1016/j.biotech.2004.05.004, 2005a.

Misselbrook, T. H., Nicholson, F. A., Chambers, B. J., and Johnson, R. A.: Measuring ammonia emissions from land applied manure: an intercomparison of commonly used samplers and techniques, Environ. Pollut., 135, 389-397, doi:10.1016/j.envpol.2004.11.012, 2005 b.

Misselbrook, T. H., Scholefield, D., and Parkinson, R.: Using time domain reflectometry to characterize cattle and pig slurry infiltration into soil, Soil Use Manage., 21, 167-172, doi:10.1079/SUM2005316, 2005c.

Müller, U.: Entwicklung optimaler Mess- und Auswertestrategien für die FTIR-spektrometrische Atmosphärenanalytik, vol. 15/226 of Fortschritt-Berichte VDI, VDI Verlag, Düsseldorf, 2000.

Neftel, A., Spirig, C., and Ammann, C.: Application and test of a simple tool for operational footprint evaluations, Environ. Pollut., 152, 644-652, doi:10.1016/j.envpol.2007.06.062, 2008.

Nemitz, E., Dorsey, J. R., Flynn, M. J., Gallagher, M. W., Hensen, A., Erisman, J.-W., Owen, S. M., Dämmgen, U., and Sutton, M. A.: Aerosol fluxes and particle growth above managed grassland, Biogeosciences, 6, 1627-1645, doi:10.5194/bg-6-1627- 
2009, 2009.

Norman, M., Hansel, A., and Wisthaler, A.: O2+ as reagent ion in the PTR-MS instrument: Detection of gas-phase ammonia, Int. J. Mass Spectrom., 265, 382-387, doi:10.1016/j.ijms.2007.06.010, 2007

Norman, M., Spirig, C., Wolff, V., Trebs, I., Flechard, C., Wisthaler, A., Schnitzhofer, R., Hansel, A., and Neftel, A.: Intercomparison of ammonia measurement techniques at an intensively managed grassland site (Oensingen, Switzerland), Atmos. Chem. Phys., 9, 2635-2645, doi:10.5194/acp-9-2635-2009, 2009

Pain, B. F., Phillips, V. R., Clarkson, C. R., and Klarenbeek, J. V.: Loss of nitrogen through ammonia volatilization during and following the application of pig or cattle slurry to grassland, J. Sci. Food Agr., 47, 1-12, 1989.

Parrish, D. D. and Fehsenfeld, F. C.: Methods for gas-phase measurements of ozone, ozone precursors and aerosol precursors, Atmos. Environ., 34, 1921-1957, 2000.

Reidy, B., Dämmgen, U., Döhler, H., Eurich-Menden, B., van Evert, F. K., Hutchings, N. J., Luesink, H. H., Menzi, H., Misselbrook, T. H., Monteny, G. J., and Webb, J.: Comparison of models used for national agricultural ammonia emission inventories in Europe: Liquid manure systems, Atmos. Environ., 42, 34523464, doi:10.1016/j.atmosenv.2007.04.009, 2008a.

Reidy, B., Rhim, B., and Menzi, H.: A new Swiss inventory of ammonia emissions from agriculture based on a survey on farm and manure management and farmspecific model calculations, Atmos. Environ., 42, 3266-3276, doi:10.1016/j.atmosenv.2007.04.036, 2008b.

Reis, S., Pinder, R. W., Zhang, M., Lijie, G., and Sutton, M. A.: Reactive nitrogen in atmospheric emission inventories, Atmos. Chem. Phys., 9, 7657-7677, doi:10.5194/acp-9-7657-2009, 2009.

Rochette, P., Guilmette, D., Chantigny, M. H., Angers, D. A., MacDonald, J. D., Bertrand, N., Parent, L. E., Cote, D., and Gasser, M. O.: Ammonia volatilization following application of pig slurry increases with slurry interception by grass foliage, Can. J. Soil Sci., 88, 585-593, 2008.

Sanz, A., Misselbrook, T., Sanz, M. J., and Vallejo, A.: Use of an inverse dispersion technique for estimating ammonia emission from surface-applied slurry, Atmos. Environ., 44, 999-1002, doi:10.1016/j.atmosenv.2009.08.044, 2010.

Schmid, H. P.: Footprint modeling for vegetation atmosphere exchange studies: a review and perspective, Agr. Forest Meteorol., 113, 159-183, 2002.

Sintermann, J., Spirig, C., Jordan, A., Kuhn, U., Ammann, C., and Neftel, A.: Eddy covariance flux measurements of ammonia by high temperature chemical ionisation mass spectrometry, Atmos. Meas. Tech., 4, 599-616, doi:10.5194/amt-4-599-2011, 2011.

Søgaard, H. T., Sommer, S. G., Hutchings, N. J., Huijsmans, J. F. M., Bussink, D. W., and Nicholson, F.: Ammonia volatilization from field-applied animal slurry - the ALFAM model, Atmos. Environ., 36, 3309-3319, 2002.

Sommer, S. G. and Hutchings, N. J.: Ammonia emission from field applied manure and its reduction - invited paper, Eur. J. Agron., $15,1-15,2001$

Sommer, S. G. and Jacobsen, O. H.: Infiltration of slurry liquid and volatilization of ammonia from surface applied pig slurry as affected by soil water content, J. Agr. Sci., 132, 297-303, 1999.

Sommer, S. G. and Olesen, J. E.: Effects of dry-matter content and temperature on ammonia loss from surface-applied cattle slurry, J. Environ. Qual., 20, 679-683, 1991.

Sommer, S. G. and Sherlock, R. R.: pH and buffer component dynamics in the surface layers of animal slurries, J. Agr. Sci., 127, 109-116, 1996.

Sommer, S. G., Olesen, J. E., and Christensen, B. T.: Effects of temperature, wind speed and air humidity on ammonia volatilization from surface applied cattle slurry, J. Agr. Sci., 117, 91-100, 1991.

Sommer, S. G., Génermont, S., Cellier, P., Hutchings, N. J., Olesen, J. E., and Morvan, T.: Processes controlling ammonia emission from livestock slurry in the field, Eur. J. Agron., 19, 465-486, doi:10.1016/S1161-0301(03)00037-6, 2003.

Sommer, S. G., McGinn, S. M., and Flesch, T. K.: Simple use of the backwards Lagrangian stochastic dispersion technique for measuring ammonia emission from small field-plots, Eur. J. Agron., 23, 1-7, doi:10.1016/j.eja.2004.09.001, 2005.

Sommer, S. G., Jensen, L. S., Clausen, S. B., and Søgaard, H. T.: Ammonia volatilization from surface-applied livestock slurry as affected by slurry composition and slurry infiltration depth, J. Agr. Sci., 144, 229-235, doi:10.1017/S0021859606006022, 2006.

Spirig, C., Flechard, C. R., Ammann, C., and Neftel, A.: The annual ammonia budget of fertilised cut grassland - Part 1: Micrometeorological flux measurements and emissions after slurry application, Biogeosciences, 7, 521-536, doi:10.5194/bg-7-521-2010, 2010 .

Sutton, M. A., Fowler, D., and Moncrieff, J. B.: The exchange of atmospheric ammonia with vegetated surfaces, 1., Unfertilized vegetation, Q. J. Roy. Meteorol. Soc., 119, 1023-1045, 1993.

Sutton, M. A., Nemitz, E., Milford, C., Fowler, D., Moreno, J., Jose, R. S., Wyers, G. P., Otjes, R. P., Harrison, R., Husted, S., and Schjoerring, J. K.: Micrometeorological measurements of net ammonia fluxes over oilseed rape during two vegetation periods, Agr. Forest Meteorol., 105, 351-369, 2000.

Sutton, M. A., Nemitz, E., Milford, C., Campbell, C., Erisman, J. W., Hensen, A., Cellier, P., David, M., Loubet, B., Personne, E., Schjoerring, J. K., Mattsson, M., Dorsey, J. R., Gallagher, M. W., Horvath, L., Weidinger, T., Meszaros, R., Dämmgen, U., Neftel, A., Herrmann, B., Lehman, B. E., Flechard, C., and Burkhardt, J.: Dynamics of ammonia exchange with cut grassland: synthesis of results and conclusions of the GRAMINAE Integrated Experiment, Biogeosciences, 6, 2907-2934, doi:10.5194/bg-6-29072009, 2009.

Thorman, R. E., Hansen, M. N., Misselbrook, T. H., and Sommer, S. G.: Algorithm for estimating the crop height effect on ammonia emission from slurry applied to cereal fields and grassland, Agron. Sustain. Dev., 28, 373-378, doi:10.1051/agro:2008013, 2008.

Tuzson, B., Hiller, R. V., Zeyer, K., Eugster, W., Neftel, A., Ammann, C., and Emmenegger, L.: Field intercomparison of two optical analyzers for $\mathrm{CH}_{4}$ eddy covariance flux measurements, Atmos. Meas. Tech., 3, 1519-1531, doi:10.5194/amt-3-15192010, 2010.

Uusi-Kämppä, J. and Mattila, P. K.: Nitrogen losses from grass ley after slurry application - surface broadcasting vs. injection, Agr. Food Sci., 19, 327-340, 2010.

van Haarlem, R. P., Desjardins, R. L., Gao, Z., Crenna, T. K., and $\mathrm{Li}, \mathrm{X}$. : Methane and ammonia emissions from a beef feedlot in 
western Canada for a twelve-day period in the fall, Can. J. Anim. Sci., 88, 641-649, 2008.

Vandre, R. and Clemens, J.: Studies on the relationship between slurry $\mathrm{pH}$, volatilization processes and the influence of acidifying additives, Nutr. Cycl. Agroecosys., 47, 157-165, 1997.

Vandre, R., Clemens, J., Goldbach, H., and Kaupenjohann, M.: $\mathrm{NH} 3$ and $\mathrm{N} 2 \mathrm{O}$ emissions after landspreading of slurry as influenced by application technique and dry matter-reduction, 1 ., NH3 emissions, Z. Pflanz. Bodenkunde, 160, 303-307, 1997.

von Bobrutzki, K., Braban, C. F., Famulari, D., Jones, S. K., Blackall, T., Smith, T. E. L., Blom, M., Coe, H., Gallagher, M., Ghalaieny, M., McGillen, M. R., Percival, C. J., Whitehead, J. D., Ellis, R., Murphy, J., Mohacsi, A., Pogany, A., Junninen, H., Rantanen, S., Sutton, M. A., and Nemitz, E.: Field inter-comparison of eleven atmospheric ammonia measurement techniques, Atmos. Meas. Tech., 3, 91-112, doi:10.5194/amt-3-91-2010, 2010.
Whitehead, J. D., Twigg, M., Famulari, D., Nemitz, E., Sutton, M. A., Gallagher, M. W., and Fowler, D.: Evaluation of laser absorption spectroscopic techniques for eddy covariance flux measurements of ammonia, Environ. Sci. Technol., 42, 2041-2046, doi:10.1021/es071596u, 2008.

Wolff, V., Trebs, I., Ammann, C., and Meixner, F. X.: Aerodynamic gradient measurements of the $\mathrm{NH}_{3}-\mathrm{HNO}_{3}-\mathrm{NH}_{4} \mathrm{NO}_{3}$ triad using a wet chemical instrument: an analysis of precision requirements and flux errors, Atmos. Meas. Tech., 3, 187-208, doi:10.5194/amt-3-187-2010, 2010.

Zhang, Y., Wu, S., Krishnan, S., Wang, K., Queen, A., Aneja, V. P., and Arya, S. P.: Modeling agricultural air quality: Current status, major challenges, and outlook, Atmos. Environ., 42, 3218-3237, doi:10.1016/j.atmosenv.2007.01.063, 2008. 